\title{
ADORNO EN DIÁLOGO CON KANT
}

\author{
Marcos Hernández Jorge \\ marhern@ull.es \\ Universidad de La Laguna \\ Carlos Marzán Trujillo \\ cmarzan@ull.es \\ Universidad de La Laguna
}

\section{RESUMEN}

Las páginas que vienen a continuación intentan mostrar algunos de los momentos en los que Adorno se ocupó de la filosofía kantiana y esbozar el papel que ésta desempeñó en su pensamiento; un pensamiento que pretendió abrir nuevos modelos con los que afrontar la realidad de su época.

Palabras Clave: bloque, crítica inmanente, sujeto transcendental, materialismo, dialéctica, metafísica.

\section{ADORNO IN DIALOGUE WITH KANT}

\section{Abstract}

The pages that follow attempt to show some moments in which Adorno took care of the kantian philosophy and to outline the paper that this one carried out in its thought; a thought that tried to open new models with which to face the reality of his time.

KEYWORDs: block, immanent criticism, transcendental subject, materialism, dialectics, metaphysics. 
La Teoría crítica, en su intento de captar su época en pensamientos, integró diferentes corrientes filosóficas: Hegel, Schopenhauer, Nietzsche, Marx, Weber, la fenomenología o el psicoanálisis. Pero también la filosofía de Kant desempeñará un papel clave en ese proyecto filosófico. Para Adorno -tanto como para HorkheimerKant constituyó un punto de apoyo fundamental para abordar el presente filosófico y confrontarlo al idealismo, al irracionalismo o al pensamiento ontologizante. Y ello a causa de su potencia reflexiva y crítica, de su rechazo al dogmatismo y, también, porque ese espíritu de autorreflexión y de lucha no se detiene ante sus propias contradicciones y las lleva al límite. A pesar de las oposiciones y ambigüedades que atraviesan la filosofía kantiana -algo valorado positivamente por Adorno y Horkheimer porque la consideran una muestra de su honestidad y profundidad intelectual-, su crítica de la razón puso límites a lo absoluto e impidió el tránsito hacia mundos inteligibles. Sin embargo, la prohibición de «irse de mundos inteligibles» contenía, al mismo tiempo, el reconocimiento de lo absoluto, cuya determinación no era posible para la Teoría crítica ${ }^{1}$. El proceder de Kant ponía de manifiesto el carácter condicionado, limitado y finito de todo conocimiento. Con ello cerraba la puerta a la afirmación de entidades esenciales o esferas de la realidad donadoras de sentido fuera del tiempo y de la historia. Sin embargo, «el muro de protección contra la reacción intelectual» que, según Horkheimer ${ }^{2}$, levanta Kant no le impide vislumbrar los peligros paralizantes de una racionalidad humana circunscrita a los estrechos límites de una experiencia reducida a las categorías del entendimiento que empobrece la realidad y excluye la razón de aquellos ámbitos en los que se juega el destino vital de los seres humanos. En ese sentido, la Teoría crítica verá en la obra kantiana un intento de intervenir en la dialéctica de la Ilustración allí donde ésta amenaza con abolir la razón misma.

Adorno confesó que el pensamiento de Kant está en la génesis de su Dialéctica negativa (como una suerte de crítica inmanente al idealismo trascendental). En esa obra recurre a él no solo como uno de sus «modelos» para hablar de la dialéctica, sino que le dedica buena parte de sus "meditaciones sobre la metafísica». Además, lo concibe como uno de los pilares en su defensa de la Ilustración. Kant (frente a Hegel y al poder que éste le otorgaba al espíritu) representaba un arma para pensar en la razón y en sus límites, no solo para sostener -al modo en que aparece en la «Dialéctica trascendental»- el carácter problemático de lo real, sino para fundamentar su dialéctica negativa a partir de las tensiones que dejaba abiertas en las antinomias

${ }^{1}$ Siempre se ha considerado como un rasgo característico de la Teoría crítica el no positivizar la utopía, el mostrar más lo que no debe ser que lo debería ser. Ese rasgo de raigambre judaica lo encuentran también en el pensamiento de Kant. Como afirmaba Horkheimer: «La prohibición judía de representar a Dios y la kantiana de abandonarse a mundos inteligibles contienen, simultáneamente, eso, que la determinación de lo absoluto es imposible». Horkheimer, M. Gesammelte Schriften, Frankfurt a. M., Fischer, 1985 y ss., vol. 6, p. 419.

${ }^{2}$ Horkheimer, M. Op. cit., vol. 11, p. 276. 
entre forma y contenido, entre sujeto y objeto. Si de Kant cuestiona sus empeños fundamentalistas, o su idea de una razón formal e in mutable, asume su pensamiento no tanto como una teoría del conocimiento sino, más bien, como una filosofía del «final del conocimiento», pues a partir de ella el pensar podría devenir en mera operatividad, en mutilación de la reflexión. A eso fue a lo que denominó «doctrina kantiana del bloque ${ }^{3}$, que estrechaba la experiencia al ámbito del saber científico. Si Kant había expresado su asombro por el desarrollo de las ciencias (sobre todo de la física newtoniana), para la Teoría crítica, y para Adorno en particular, el saber científico, sobre todo en sus versiones más positivistas, se revelaba como decepción, pues se había convertido en un obstáculo para el pensar mismo porque se abandonaba a lo meramente fáctico. De ahí el empeño por minar, desde sus grietas, el «bloque kantiano" para poder vislumbrar significados y sentidos más allá de lo dado. En ese empeño optará por la dialéctica hegeliana, aunque rechazará el carácter afirmativo de la misma que acaba sacrificando lo particular en favor de lo universal. Tratará, más bien, de abrir un espacio al pensamiento susceptible de una aproximación no idéntica del mismo.

Para Adorno, la continuidad de la filosofía dependía, en gran medida, de perseverar en el camino abierto por Kant que consideró la crítica no solo como una forma de conocimiento, sino también como un programa al que le era inherente una pretensión moral. En este sentido, para él, la obra de Kant trató de pensar las condiciones de posibilidad de la humanización de la sociedad burguesa, apelando al uso no tutelado de la razón en todos sus ámbitos. Es decir, la salida del individuo «de su autoculpable minoría de edad». De ahí que sostuviera que «hay que dar por supuestos el valor y la capacidad de cada uno para servirse de su entendimiento. Si no nos aferramos a éstos, el discurso entero sobre la grandeza de Kant queda reducido a simple retórica, a homenaje de boca para afuera $»^{4}$. La lectura que hizo de los textos de Kant, introduciéndose en sus grietas y fisuras, y considerándola como un «campo de fuerzas» (yendo más allá de la obsesión kantiana por la armonía y coherencia de su sistema), le permitió desvelar las tensiones y contradicciones que caracterizan la experiencia del mundo burgués y, con ello, determinar la potencia y los límites de la filosofía kantiana y, por extensión, del proyecto ilustrado que va de Kant a Marx. Ese proyecto, que para Adorno es la filosofía misma, seguía vigente. En aras de su

${ }^{3}$ Con el concepto de «bloque kantiano», Adorno y Horkheimer expresaron en diversas ocasiones la escisión que Kant establecía entre, por un lado, la estética y la analítica trascendental y, por otro, la dialéctica trascendental. Es decir, la diferencia entre la síntesis de la sensibilidad y el entendimiento, entendida como facultad mecánica de conocer (Verstand), y la razón (Vernunft) como facultad que aspira a ir más allá de lo dado. Cfr., por ejemplo, Adorno, Th.W. Kants "Kritik der reinen Vernunft», Nachgelassene Schriften, Tiedemann, R. (ed.), Frankfurt am Main, Suhrkamp, 1995, IV, 4 p. 34. En adelante los escritos póstumos de Adorno se citarán con abreviatura $N g$. seguida del número de volumen y la página. Por otra parte, la obra completa de Adorno será citada según: Th.W. Adorno, Gesammelte Schriften, Adorno, G. y Tiedemann, R. (eds.), Frankfurt am Main, Suhrkamp, 1973 y ss.

${ }_{4}^{4}$ Adorno, Th.W. Erziehung zur Mündigkeit. Vorträge und Gespräche mit H. Becker 19591969. Kadelbach, G. (ed.), Frankfurt am Main, Suhrkamp, 1970, p. 133. 
posibilidad pensaba que era necesario someterlo a una revisión crítica sin concesiones. No pretendía tanto, pues, una vuelta a Kant, como planteaban los neokantianos, sino asumir desde él la idea y la necesidad de que el proyecto ilustrado pudiese ser realizado. Su transformación y renovación se concretaba en «ilustrar la Ilustración» sobre sí misma. Esto es, en establecer los límites a una razón identificadora incapaz de abrirse a lo otro del pensamiento, a eso que denominaría lo «no-idéntico». La función que adjudicó a la filosofía en el sentido de resolver la disyunción entre intuición y concepto, así como la forma de pensar dialéctica y negativa que puso a su base, expresaba tanto la transformación como la actualidad del programa crítico kantiano. Ese pensar se hallaba transido de un nuevo imperativo moral: «Que Auschwitz no se repita». El pensar dialéctico y negativo debería recoger no solo la potencialidad que trasciende el presente y que se desarrolla en su seno, sino también, y en mayor medida, todo eso que la sociedad deja de lado: los materiales de desecho, las ruinas, lo que no encaja en su devenir histórico; en definitiva, activar eso que denominaron "la anamnesis de la naturaleza en el sujeto». De ese modo, la crítica tendría que remitirse a lo opaco, a lo inaprehensible, que, como tal, tiene algo de anacrónico, pero que no se convierte en anticuado, porque en cualquier momento puede golpear a la dinámica histórica (Cfr. GSA 4, 172).

Adorno no escribió ningún ensayo dedicado a interpretar la obra de Kant, como lo hizo con las de Kierkeggard, Husserl, Heidegger o Hegel. Sin embargo, Kant ocupa un lugar destacado en algunos de sus textos más conocidos como el excurso sobre Juliette -escrito junto a Horkheimer-en Dialéctica de la Ilustración, o las reflexiones que le dedica en Dialéctica negativa o Teoría estética. Kant constituye también uno de los ejes centrales de sus lecciones académicas desde que, tras su exilio americano, retorna a Fráncfort y se incorpora, en octubre de 1949, como profesor extraordinario en la Goethe Universität. Esas lecciones sobre Kant -que han sido recogidas en sus escritos póstumos- se encontraban abarrotadas de estudiantes que llegaron a solicitarle, como da cuenta en su correspondencia, que las prorrogara durante el periodo vacacional. Entre esas lecciones cabría destacar la dedicada a la Crítica de la razón pura ${ }^{5}$, en la que se había introducido siendo adolescente junto a

5 Esas lecciones no buscaban tanto describir o explicar la obra de Kant, sino verla como un ensayo cargado de experiencias intelectuales que podían servir para cuestionar el presente del sujeto pensante. Trataba de leer esos textos de manera que pudieran objetivarse y saliesen a la luz las experiencias que en ellos se encerraban. Un análisis de su lectura sobre la Crítica de la razón pura se encuentra en Thornhill, Ch. "Adorno Reading Kant», en Studies in Social and Political Thought, n. ${ }^{\circ}$ 12, Univ. of Sussex, 2006, pp. 98-110. Sobre la relación Adorno-Kant, cfr., Kritische Theorie versus Kritizismus. Zur Kant Kritik Th.W. Adornos, Funke, G. y Kopper, J. (eds.), Kantstudien 115, Mainz, De Gruyter, 1982. 
su amigo Siegfried Kracauer, quien, como escribió, le hacía «oír la voz de Kant» ${ }^{6}$. Y entre los maestros universitarios que marcaron su lectura temprana de Kant, habría que citar a Hans Cornelius, que impartía docencia en Fráncfort en el periodo en que era estudiante (1921-1924), y cuya manera de abordar el criticismo difería del neokantismo que se estilaba en la Alemania de la época. Frente a las tesis neokantianas que ahondaban en el idealismo trascendental y que sostenían que la validez de los conocimientos se apoyaba en determinadas estructuras lógicas, Cornelius -influido por la Gestalt-mantenía que dicha validez se vinculaba con estructuras psicológicas? De ahí que considerara necesario indagar la génesis de los conocimientos. Bajo su influencia, Adorno concluiría en 1927 un escrito de habilitación que, debido a los consejos de su maestro, no llegó a presentar, pues lo consideraba poco original y demasiado próximo a las ideas que éste había expuesto en su Sistemática trascendental.

Desde sus comienzos intelectuales Adorno asumió la tesis de que no es posible elaborar ninguna filosofía sin vincularse a su historia; que la historicidad interna del pensamiento se halla entrelazada con el pasado filosófico. Es decir, que no cabe hacer filosofía desgajándola de la historia de la filosofía, pues todo «ahora» es «unidimensional» ${ }^{8}$. La tradición en general, y la filosófica en particular, constituyen,

6 «Los sábados por la tarde [Kracauer] la leía regularmente conmigo. No exagero en absoluto si digo que debo más a esa lectura que a mis maestros académicos». En ocasiones, la pasión musical de Adorno le impulsaba, incluso, a tratar de interpretar la Crítica kantiana al piano. Adorno escribió un ensayo dedicado a Kracauer, «Der wunderliche Realist», donde narra esas lecturas, y que se encuentra en el volumen 11 de sus obras completas. Acerca de las relaciones intelectuales entre Adorno y Kracauer, $c f r$. S. Müller-Doohm, «Das Erste Mentor: Siegried Kracauer», en Klein, R. et al. (eds.), Adorno Handbuch, Leben, Werk und Wirkung, Stuttgart, Metzler, 2011. Las lecturas de Kant que hacía con Kracauer entendían el texto como un escrito cifrado que servía para ahondar en «el estado histórico del espíritu». Esto es, perseguían vincular la abstracción filosófica con la filosofía concreta, relacionar los conceptos con la realidad de la que surgían. En este sentido, Adorno llegaría a considerar la Crítica de la razón pura como expresión de la resignación burguesa, pues se mantenía en lo finito sin ser capaz de decir nada esencial sobre las cuestiones decisivas. La primera Crítica kantiana era, para él, «una teodicea de la existencia burguesa [...] que es consciente de su propia praxis y pone en duda su utopía» (Ng IV. 4, 17). Esa manera de enfrentarse a Kant por parte del joven Adorno prefigura la especificidad de su interpretación de la filosofía kantiana frente a las lecturas de algunos autores de la filosofía contemporánea, como pueden ser, entre otras, las de Heidegger o Strawson.

7 En sus lecturas de Kant, Adorno recurría con frecuencia al ensayo de Cornelius, H. Kommentar zu Kants Kritik der reinen Vernunft, Erlangen, Philosophischen Akademie, 1926, sobre todo a aquellas tesis que ponían en cuestión uno de los temas centrales de la Crítica de la razón pura, la idea de juicios sintéticos a priori, o que la distinción entre juicios analíticos y sintéticos no era nítida. Así, Cornelius sostenía que afirmar que el color naranja está en la escala cromática entre el rojo y el amarillo «tiene validez para todas las experiencias futuras y, en este sentido es un juicio sintético $a$ priori [...]. Pero es incuestionable que este juicio procede de la experiencia y no del pensamiento puro». También planteaba, por ejemplo, que la proposición “Todos los cuerpos son pesados" es sintética sólo si el concepto de 'cuerpo' es entendido en el sentido de cuerpo geométrico. Si, por el contrario, ese concepto, es presupuesto en un laboratorio químico contendría la característica de la pesantez, y ese juicio resultaría analítico» (p. 31 y ss.).

${ }^{8}$ Como escribió R. Tiedemann, «en el pensamiento de Adorno todavía es posible divisar la topografía de la filosofía tradicional que se desarrolla como teoría del conocimiento y como teoría de la sociedad», Tiedemann, R. «Begriff, Bild, Name. Über Adornos Utopie von Erkentniss», 
para él, componentes «cuasitrascendentales»; mecanismos que, de manera similar a la doctrina del esquematismo kantiano, se ocultan en las "profundidades del alma humana» o, más exactamente, «en las profundidades de cualquier problemática filosófica», pues se encuentran a la base de todo pensar. Asumir esas componentes, sin renunciar a la crítica y a la reflexión, mueven su pensamiento desde sus primeros trabajos académicos, en los que se posicionaba frente a las filosofías de su tiempo. Era consciente de que no cabía establecer un manual de instrucciones para leer los textos clásicos de la filosofía. Insinuaba que solo cabía el esfuerzo del pensar, la formación constante y cierto grado de sensibilidad y creatividad (eso que, en ocasiones, llamó "fantasía exacta») a sabiendas de los riesgos que conlleva el paso «entre la Escila y el Caribdis» de la interpretación, entre la literalidad y el excesivo alejamiento del texto, que implica toda lectura filosófica y que conducen, igualmente, a interpretaciones fallidas. El peligro de caer en la arbitrariedad solo quedaba limitado por el texto, que estaba ahí de manera irrevocable.

Su lectura de Kant -tanto como la que hizo de otros autores- no buscaba reconstruir el lugar concreto que éste ocupaba en la historia de la filosofía. Tampoco pretendía establecer -algo imposible de reconstruir- lo que esos autores se planteaban con su filosofía, es decir, sus intenciones, ni ver sus pensamientos como algo cerrado en sí mismo y exento de contradicciones. Pensaba, más bien, que solo desde éstas, desde sus fricciones, era posible ir más allá de los textos. Consideraba que la consistencia sistemática de una filosofía no permitía que ésta pudiera expresarse en profundidad. Al contrario, era precisamente en sus grietas, en sus contradicciones, donde se mostraba la relevancia de un pensamiento, las dificultades de los problemas de los que se ocupaba. Traerlas a la conciencia y reconocerlas en su carácter de necesidad constituían el eje de sus interpretaciones textuales, que se ocupaban más del significado de un pensamiento que de aquello que pretendía expresar.

Trató de leer los textos clásicos de la filosofía a través de lo que denominó "crítica inmanente». Con ella perseguía ahondar en las contradicciones que se hallaban en el interior de los pensamientos filosóficos con el fin de cuestionar sus componentes idealistas y, al tiempo, trascenderlos. Esa "crítica inmanente», frente a lo que llamó "filosofía de un punto de vista» o "concepción del mundo», consistía en una estrategia hermenéutica que evitaba partir de planteamientos externos al texto que solían estar cargados de arbitrariedad y rigidez. Para él, esa "filosofía del punto de vista» se limitaba a convertir determinadas opiniones y perspectivas filosóficas en un sistema desde el que se podía interpretar un pensamiento desde una «zona de confort», capaz de sustraerse a la crítica, al rigor y al esfuerzo: «El desinterés por la argumentación del otro -afirmó- hace que se incurra fácilmente en una postura dogmática»" La filosofía-como decía en sus clases- debería consistir en «el examen

p. 71, en Löвeig, M. y Schweppenhëuser, G. (eds.), Hamburger Adorno-Symposion, Grunewald, Lüneburg, 1984.

9 Adorno, Th.W. Philosophisches Terminologie I. Frankfurt am Main, Suhrkamp, 1973, p. 134. 
independiente de todo contenido espiritual dado"; una idea que cifraba en la palabra "crítica» y que, para él, seguía haciendo actual al pensamiento kantiano.

El ideal regulativo de su "crítica inmanente» planteaba, pues, la necesidad de leer las obras sin presupuestos previos, sin reservas mentales, para sumergirse en el objeto textual y contribuir, de ese modo, «a la extracción de la sustancia objetiva de los textos». De ahí que no considerase fundamental definir los conceptos, sino -más bien- mostrarlos, para tratar de proporcionarles un sentido concreto. Para él, elaborar algo así como una «valoración crítica» -tan habitual en el gremio profesoral con ocasión de algún acontecimiento cronológico relativo a algún autor-le resultaba «una presunción arrogante con la que se pretendía señalar un determinado puesto al difunto y colocarse por encima de él» (GSA 5, 247). Esas valoraciones críticas -como anotaba en sus comentarios sobre Hegel- solían partir de la pregunta acerca del significado que tenían para el presente las obras de la filosofía del pasado, en lugar de partir de la pregunta inversa, esto es, lo que significaba el presente ante el pensamiento de algunos clásicos. Así, por ejemplo, ante Kant, si su idea de Ilustración, de reconciliación o de una razón de la que puedan participar todos los seres humanos se hallaba rezagada respecto a la realidad en la que vivían. Pero esa "crítica inmanente» también se oponía a lo que se ha llamado «morbo hermenéutico». Es decir, a la conversión del pensamiento en mera filología. Tal filologización de la filosofía podía propiciar que «la discusión sobre lo pensado en sus textos por los filósofos se sustituya por la pregunta acerca de lo que dicen los textos», a que se sobrevalore la literalidad del texto frente al esfuerzo por el pensar.

A mediados de los años cincuenta Adorno impartió diversos seminarios sobre la filosofía kantiana en los que ejercitó ese tipo de crítica textual e inmanente. Entre ellos, una introducción a la Crítica de la razón práctica (1954-55), uno -junto a Horkheimer- sobre la Crítica del juicio, y otro sobre «La lógica trascendental» (1955). Pero la lectura más sistemática que hizo sobre Kant se encuentra en sus lecciones de 1959 (que coinciden con el comienzo de la elaboración de su Dialéctica negativa), cuando dedica un semestre a la Crítica de la razón pura. En esas lecciones no trató de hacer una interpretación histórica de la obra de Kant, sino una «objetiva», que apuntara a los problemas filosóficos que latían en ella. En esas lecciones sostenía que la lectura de Kant suponía una experiencia filosófica de gran dificultad, pues «en un estricto seguimiento al texto mismo - para quien no esté familiarizado con la Crítica de la razón pura- no le quedarán absolutamente claras algunas cosas, pero si uno se aleja demasiado, comentando libremente el texto, corre el peligro de proyectar sobre él motivaciones propias y, con ello, herir el respeto que [...] debemos a un gran autor como Kant» ${ }^{10}$. Esas lecciones trataban de descubrir «una especie de campos de fuerzas», para hallar, dentro de su aparente armonía y coherencia, «elementos contrapuestos que pugnan entre sí» y que desvelan la experiencia de la existencia burguesa. Su crítica inmanente a la obra de Kant se combinaba con una suerte de

\footnotetext{
${ }^{10}$ Adorno, Th.W. Philosophische Terminologie I, Frankfurt am Main, Suhrkamp, 1973,
} p. 105. 
«mirada micrológica» (que prestaba atención a pasajes, conceptos y expresiones que solían ser leídos de modo superficial), usando la estrategia, heredada de su amigo Benjamin, de las constelaciones conceptuales, que consistía en aproximarse a las ideas del texto desde diferentes ángulos y perspectivas. Pretendía ir más allá de los tecnicismos terminológicos kantianos y otorgar solo una importancia relativa a los que han sido considerados pasajes canónicos de la obra, para centrarse -en ocasiones-en otros sobre lo que ha pasado casi de puntillas la historiografía filosófica. Avanzaba y retrocedía en torno a determinados temas (como los de "juicios sintéticos a priori», «cosa», «trascendental», «yo» o «esquematismo»), con objeto de "hacer hablar a la obra» y reavivar lo que había quedado solidificado en esos conceptos. Para leer a Kant recomendaba no aferrarse a sus definiciones, sino considerarlas en torno al contexto y las constelaciones en los que aparecían.

Ese esfuerzo por leer a los clásicos de manera productiva, y en concreto a Kant, se encuentra por primera vez en su escrito de habilitación, que llevaba por título El concepto de inconsciente en la psicología trascendental, publicado póstumamente a petición propia, pues lo consideró excesivamente idealista. El texto partía de presupuestos kantianos, de la crítica al dogmatismo y al ontologismo psicológico; presupuestos que pretendía hacer coincidir con el psicoanálisis de Freud con objeto de «desencantar» el concepto de inconsciente. Pues, para él, tanto el psicoanálisis como el trascendentalismo kantiano coincidían en la tesis «de la unidad y legalidad del curso de la conciencia» (GSA 1, 315). Eso es lo que le hizo entender el psicoanálisis como epistemología. Planteaba que las denominadas "filosofías del inconsciente», asociadas a autores como Herder, Jacobi, Schelling, Schopenhauer, Nietzsche o Bergson, etiquetadas bajo la denominación de irracionalismo o vitalismo, habían surgido como rechazo a la razón teórica kantiana y pretendían encontrar espacios para la trascendencia, para esencialidades independientes de la experiencia. Pensaba que esas filosofías hipostatizaban los conceptos límite kantianos, que vinculaban la cosa en sí con el inconsciente. El propósito del escrito de habilitación era sentar las bases para una "teoría trascendental del inconsciente». Algo que, en su opinión, requería partir de Kant "para ir más allá de Kant». Su intención era "corregir y, en ocasiones, completar, el análisis kantiano de la psicología racional» (GSA 1, 175) apoyándose en las ideas que Cornelius había expuesto en su Sistemática trascendental.

A pesar del carácter juvenil y escolar de este ensayo, aparecen elementos que serán una constante en su obra posterior: no solo el interés en la obra de Kant o Freud, sino la idea de que teoría del conocimiento y crítica social se hallaban entrelazadas. En las conclusiones señalaba la función ideológica de las doctrinas del inconsciente, pues apuntaban a fuerzas trascendentes capaces de sustraerse a las tendencias económicas y racionalizadoras del presente. Puso de relieve una contradicción que vertebra la crítica kantiana y que consiste en que, por una parte, la idea de sujeto trascendental no puede ser pensada sin el sujeto empírico y, de otra, que éste se halla constituido por aquél. A sus ojos, Kant era consciente de esa contradicción en 
la que debió incurrir por la intención antipsicológica de su pensamiento, pues para Kant, «la unidad de la apercepción», la esfera de la subjetividad trascendental, debía estar exenta de facticidad, debía ser considerada independiente de toda experiencia.

La lectura que hace de la Crítica de la razón pura a partir de este ensayo prestará especial atención al capítulo de los paralogismos, al que considera una de las claves del momento ilustrado de la obra, pues cuestionaba la denominada "psicología racional», que definía el alma como sustancia simple e inmortal. Frente a la psicología racional, Kant sostenía que de la reflexión sobre la unidad de la consciencia no cabía derivar su carácter sustancial. Es decir, que el percatarse del Sí mismo es algo meramente abstracto, una necesidad lógica sin la que no cabría pensar, pero que no se podría determinar como una entidad, pues para ello se requería de intuiciones de la sensibilidad. Esa identidad del yo es, para Kant, una unidad meramente formal que, sin embargo, es vacía sin las experiencias concretas del sujeto empírico.

Para Adorno, la crítica kantiana a la metafísica de la conciencia, a la «psicología racional», imposibilitaba entender la psicología como ciencia, pues no consideraba que la experiencia sea base del conocimiento de las leyes de la experiencia. $\mathrm{El}$ "yo pienso que acompaña a todas mis representaciones»" es entendido por Kant como independiente de la experiencia. Solo es mera posibilidad de la misma. No quiso admitir -escribe Adorno- que «la unidad de mi conciencia no es más que la unidad de mis vivencias, y no tiene validez alguna al margen de la complexión de mis vivencias» (GSA 1, 162). Esa concepción del yo es lo que, según él, también empujaría a Kant a entender lo inconsciente como un mero residuo metafísico. Por contra, las tesis del joven Adorno que ahondaban en el pensamiento de Cornelius le llevaron a mantener que el yo trascendental-como complexión de vivencias-era inseparable del yo empírico, de las vivencias efectivas de los sujetos singulares. Y, desde esta perspectiva, el "yo pienso», en tanto que sujeto del conocimiento, puede ser también objeto de conocimiento. Hay leyes del conocimiento (lo que en la Sistemática trascendental se denomina "yo fenoménico»), objeto de una psicología racional, que pueden derivarse por abstracción del yo empírico, que sería objeto de una psicología empírica. Por eso, para él, cabría elaborar «una doctrina trascendental del alma» desde la que se consideraran los elementos trascendentales como fundamentos de la experiencia que han de ser referidos siempre a ésta. Esa doctrina trascendental debería ocuparse también de lo inconsciente, cuya realidad «solo puede legitimarse recurriendo a lo consciente» (GSA 1, 203). Lo inconsciente no debería desviarse hacia mundos inteligibles, sino ser abarcado por una psicología que los esclarezca, pues «lo consciente y lo inconsciente también pertenecen al complejo de nuestra consciencia» (GSA 1, 218). El estudio de la obra de Kant por parte del joven Adorno constituye -como escribió acerca de sus primeros ensayos- una suerte de "anticipación onírica» del desarrollo de su pensamiento que tendrá en común con Kant su defensa de la Ilustración; una defensa que en este ensayo se concretaba en

${ }^{11}$ Kant, I. Kritik der reinen Vernuft, B132. 
su esfuerzo teórico por introducir la razón en la esfera del inconsciente, algo que el formalismo kantiano había dejado atrás.

A partir de este fracasado trabajo de habilitación, su pensamiento no deja de aproximarse al de Kant, al tiempo que se interesa por las obras de Hegel, Marx, Freud o Husserl. Con Kant coincide en su defensa de la Ilustración y en su compromiso con el desarrollo de un concepto positivo de la misma, con el ideal de la construcción de una humanidad que fuese capaz «de manifestar los intereses supremos de la razón $»^{12}$ para edificar una vida mejor. Pero también concuerda con él en su crítica tanto al empirismo craso como a la metafísica dogmática, o en la búsqueda de espacios donde la experiencia metafísica pudiera ser salvada (eso que en Dialéctica negativa llamará «metafísica por la ranura»). Kant desempeñará, además, un papel central a la hora de entender su concepción negativa de la dialéctica o su idea de utopía como «tierra de nadie».

\section{IV}

Con Kant -como afirmó en numerosas ocasiones- la Ilustración había llegado a la conciencia de sí misma, pues había ahondado en sus límites y posibilidades. Para Adorno - como para la Teoría crítica en general- se trataba de valorar esos límites y posibilidades desde el presente histórico, pues el momento crítico y reflexivo que Kant había introducido, el interrogar a la razón sobre sí misma, parecía haberse desvanecido definitivamente a causa de la deriva instrumental de una razón reducida, cada vez más, a entendimiento (Verstand). De ahí el empeño, que mantuvo junto a Horkheimer -en consonancia con los acontecimientos epocales-, de «ilustrar la Ilustración» sobre sí misma. Un empeño que pasaba por la reflexión acerca de que la razón no es solo poder y dominio, sino potencia para producir algo bueno y verdadero.

Se podría sostener que el proyecto filosófico de Adorno (considerado tanto globalmente como desde sus desarrollos concretos) constituye, en buena medida, un retorno a la preocupación kantiana por establecer las condiciones de posibilidad de la Ilustración. Pero ahora esas condiciones no cabría establecerlas únicamente desde la razón, sino que debían incorporar la experiencia histórica acumulada, que no solo habría puesto de manifiesto el lado oscuro del proyecto ilustrado, sino que amenazaba con hacer definitivamente inviable su propia posibilidad. Y eso ponía en cuestión tanto el propio marco teórico kantiano como el contenido temático que abordaba. De ahí que sostuviese que «entre las variantes de las preguntas que forman el punto de partida [...] de la Crítica de la Razón Pura, no debería faltar cómo un pensamiento que tiene que desprenderse de la tradición, puede conservarla transformándola» (GSA 6, 64). Ésa será una de las constantes de su pensamiento:

12 Kant, I. Op. cit., A804/B832. 
conservar y renovar el espíritu de la filosofía kantiana y, con ello, de la Ilustración misma en las condiciones de la tendencia hacia un mundo cada vez más administrado.

El tratamiento que hizo de la filosofía de Kant, la conservación y transformación de los problemas de los que éste se había ocupado, constituía un contrapeso, no solo a las filosofías idealistas, ontológicas e irracionalistas, sino también al pensamiento marxista. Kant le proporcionó, en buena medida, el ámbito de problemas filosóficos desde el que erigió no solo su reflexión sobre el papel del sujeto, sino sobre la idea de una dialéctica negativa apoyada en la radicalización de las aporías kantianas. Asumió la idea kantiana -como expuso en sus lecciones y seminarios-de que el conocimiento no se agota en la mera conceptualidad, de que en la obra kantiana aparece la cuestión de la relación entre «identidad y no-identidad», o la idea de que el sujeto y el objeto no pueden reducirse el uno al otro.

Comprender esa tensión dinámica entre la conservación y la transformación del pensamiento kantiano, aquello que, a un tiempo, lo vincula y lo separa de Kant, constituye un importante hilo conductor para interpretar una obra tan compleja como la de Adorno. Se vinculó a la filosofía kantiana tanto en su intento por proseguir el empuje racional e ilustrado como en su defensa de la crítica y la reflexión. Persistió en la idea de que la razón no ha de encerrarse en un interés meramente especulativo, sino que ha de abrirse al interés práctico, a la construcción de sentidos a la medida humana. Pero se distanció de él -y esto es algo que le separa de algunos pensadores considerados herederos de la Teoría crítica- respecto a cualquier intento de depurar abstractamente la razón o al empeño por perseguir aspiraciones fundacionalistas y normativistas sobre las que sostener la crítica. Para él, ello podría obstaculizar la posibilidad de una praxis verdaderamente autónoma y emancipatoria ${ }^{13}$. Por el contrario, siempre mantuvo que el ejercicio de la crítica debería ejercerse tanto desde una posición inmanente a la realidad como frente a los discursos que aspirasen a captarla desde un entramado sistemático de redes conceptuales; una crítica cuyo único sostén sería la denuncia de una visión de la realidad que niega la posibilidad de que las cosas pudiesen ser de otra manera.

Las reflexiones de Adorno y Horkheimer sobre la Critica de la razón pura, como se recoge en algunos de sus protocolos de discusión, daban cuenta de que esta obra constituía un pensamiento de la identidad que plasmaba eso que denominaron «bloque». Es decir, que en la Crítica kantiana se trazaba un muro entre lo que legitima la ciencia (aquello que cabe integrar en la experiencia posible organizada por el entendimiento) y lo que no se agota en ello. Una idea que mostraba el estado histórico-filosófico de una sociedad determinada por el intercambio que, al mismo tiempo, dejaba abiertas las posibilidades para algo distinto. Esto es, que el «bloque» kantiano apuntaba hacia direcciones diferentes e irreconciliadas. Creían que eso era, precisamente, lo que limitaba la pretensión de identidad que se hallaba en la

${ }^{13}$ El propio devenir dialéctico de la Ilustración habría mostrado que la vía práctico-subversiva pasaba por «la intransigencia de la teoría frente a la inconsciencia con que la sociedad permite reificarse al pensamiento» (GSA, 3, 59). 
filosofía kantiana. Y en ese sentido, en esa limitación «radica objetivamente la posibilidad del cambio y el giro contra la razón y la ilustración» (Ng IV, 4, 106). Desde esta perspectiva, Adorno interpretará la filosofía kantiana no solo como una teoría epistemológica, sino como reflejo de los fines y de la situación del conocimiento, y aunque Kant aspirase a abarcar la totalidad del conocimiento acaba concluyendo que la razón es incapaz de comprender la totalidad ${ }^{14}$. Desde sus primeras lecturas de Kant supo valorar esta tensión entre la razón entendida como límite y como expresión del dominio de la naturaleza (Verstand), pero también como impulso para superar esos límites (Vernunft). Uno de los motivos principales de su ocupación con Kant fue el de «desbloquear ese bloque», asumiendo la crítica hegeliana a Kant, pero sin compartir sus planteamientos filosóficos, a los que consideraba más idealistas que los del propio Kant ${ }^{15}$. Para él, la concepción kantiana del conocimiento no deviene, como en Hegel, identidad absoluta. Por eso pensaba que en su filosofía quedaban más espacios para lo nuevo, para la utopía: «Kant [que renunció a la construcción de la idea de Espíritu absoluto] expresó la posibilidad del cambio, de un devenir distinto del acontecer histórico de manera incomparablemente más enérgica [que Hegel] $»^{16}$. La tensión que Adorno encontró en el «bloque» erigido por Kant le llevó a confrontarlo con Hegel, pero no para sustituir su pensamiento por el de éste, sino precisamente para abrir el espacio de su teoría a una discusión permanente entre uno y otro, como modelos sobre los que construirá su concepción negativa de la dialéctica. En este sentido afirmó:

El proceso entre Kant y Hegel en el que las argumentaciones contundentes tenían la última palabra, no ha terminado aún (acaso porque lo contundente, el supremo poderío de la misma rigurosidad lógica, es una falsedad frente a las figuras kantianas). En efecto, merced a su crítica a Kant, [Hegel] amplió grandiosamente la filosofía crítica por encima del campo formal [...] escamoteó, al hacerlo, el momento crítico supremo: la crítica de la totalidad, de lo infinito como término de todo. De este modo, apartó de delante autocráticamente aquel bloque -irresoluble para la consciencia- cuya experiencia fue la más profunda que tuvo la filosofía trascendental kantiana; bloque gracias a cuyas fisuras se estipula una concordancia sin grietas del conocimiento que tiene algo de fantasmagoría crítica (GSA 5, 323-324).

${ }^{14}$ Como escribieron en Dialéctica de la Ilustración: «Kant unió la tesis del incesante y fatigoso progreso [del pensamiento] hasta el infinito, con la permanente insistencia sobre su insuficiencia y eterna limitación [...]. No hay ser en el mundo que no pueda ser penetrado por la ciencia, pero lo que puede ser penetrado por la ciencia no es el ser» (GSA 3, 43).

15 «Es cierto que Hegel, a través de la mediación, disuelve la frontera kantiana [...] más metafísico que Kant, se va de mundos inteligibles. Pero también a causa de la misma mediación; esto es, la afirmación de la existencia en la idea, lo hace más positivista [que Kant]», Adorno, Th.W. «Scribble in Book», en Perspektiven Kritischer Theorie (Ch. Türcke ed.), Lüneburg, Zu Klampen , p. 9. 1974, p. 79.

${ }^{16}$ Adorno, Th.W. Philosophische Terminologie, vol. II, Frankfurt am Main, Suhrkamp, 
Con esa intención del «desbloqueo», y frente a ese «muro kantiano», cabría entender su idea -de raigambre benjaminiana- de elaborar "constelaciones conceptuales ${ }^{17}$ (que reformula como estrategia no sistemática para evitar caer en las totalidades hegelianas), como alternativa no solo para ahondar en los pensamientos de su época desde planteamientos crítico-ideológicos, sino para abordar los problemas sociales y, con ello, potenciar perspectivas para una nueva forma de praxis emancipatoria.

Adorno también se planteó, como hizo Kant, la posibilidad de pensar más allá de los límites de la razón, pero no tanto dirigiendo sus dardos críticos contra el embrujo de la metafísica, sino sobre todo contra el hechizo de una realidad social naturalizada, que frecuentemente, se complementaban y reforzaban mutuamente. Algo que, para él, exigiría el esfuerzo del pensamiento, desenclavar a los individuos de lo dado: «El hechizo de la realidad sobre el espíritu le impide lo que desea su propio concepto frente a lo meramente dado: volar» (GSA 10.2, p., 633). Se trataría de satisfacer ese «deseo de volar» del concepto y redirigirlo contra lo que consideraba la esclerosis que en el presente sufría la praxis emancipatoria. En suma, trató de rescatar una idea de Ilustración que oponía tanto al positivismo como a las corrientes irracionalistas y antisubjetivistas que ocupaban el espacio filosófico de su época y que estará en el trasfondo de su propia concepción del materialismo. El pensamiento kantiano no es solo una de las matrices centrales sobre las que se apoya su crítica a la Ilustración -como se ha señalado-, sino también uno de los pilares que, confrontado a la temporalidad hegeliana del concepto, trata de recuperarlo desde su materialidad histórica y social en la forma de una praxis de raíz marxiana ${ }^{18}$. Las condiciones históricas en las que se habían concretado los ideales ilustrados obligaban -como desde sus comienzos percibió la Teoría crítica- a vincular la crítica kantiana al conocimiento con la crítica de la sociedad de procedencia marxiana ${ }^{19}$. Por eso consideraron que

${ }_{17}$ Establecer conceptos en forma de constelación, combinarlos alrededor de la cosa, es, para él, un elemento crítico con el que se pretende descifrar la historia sedimentada en el concepto: «Conocer el objeto en su constelación es saber el proceso que ha acumulado» (GSA 6, 166).

${ }^{18}$ Como escribía Horkheimer: «La filosofía de Marx, según la cual la teoría y la práctica son una sola cosa ya está resuelta en la filosofía kantiana. En ella, se considera al conocimiento como el producto de la actividad del sujeto, al mundo como resultado de la constitución [...]. Las mismas ideas que gobiernan regulativamente el conocimiento, indican su orientación a la razón práctica, a la acción [...]. Marx debe a Kant más de lo que alguna vez viera Max Adler», Horkheimer, M. Op. cit., vol. 6, pp. 383-384.

${ }^{19}$ En ese sentido, Horkheimer anotaba la posibilidad de una especie de «sociología kantiana»: «Escribir una crítica de la razón como Kant, sólo que elaborando los factores, el mecanismo, que produce la experiencia unificada a partir del material, consiste, en lugar de partir de las puras formas de la intuición y del entendimiento, en el esquematismo social. [...] La estética trascendental debería proceder a partir de la producción material con la que el hombre estructura inmediatamente el mundo: a partir de ella proceden los modos de percepción generales y especiales, adecuados al dominio [...], lo que Marx denominó apariencia necesaria. La analítica trascendental serían los medios de la intelectualidad social desde la escuela hasta el cine. Y la esfera de la razón (Vernunft) sería la adaptación de la sociedad a niveles cada más elevados, lo que Hegel llamó la astucia de la razón", Horkheimer, M. Op. cit., vol. 6, pp. 191-92. 
la única vía que quedaba abierta, coincidente con el espíritu filosófico kantiano, era "el camino crítico ${ }^{20}$. Cabría plantear que la dialéctica negativa de Adorno vendría a ser una cristalización en el ámbito teórico-cognoscitivo de esa idea de una sociología kantiana sobre la que especulaba Horkheimer, y que concretó en el esfuerzo por leer a Hegel desde Kant y a éste desde Marx. Lo primero podría entenderse no tanto en confrontar el idealismo trascendental al idealismo hegeliano, sino en mantener, radicalizándolas, las antinomias y grietas que Kant dejó abiertas entre lo finito y lo absoluto, en pensar que la reconciliación no está realizada de antemano y en subrayar el lado negativo de la historia. Y lo segundo, asumiendo la teoría kantiana como un anticipo de la idea de apariencia socialmente necesaria que la crítica de la economía política marxiana puso en juego, pues siempre entendió que la filosofía trascendental ponía de manifiesto que el mundo de los seres humanos es un mundo de apariencias. Un pensamiento que se encuentra en los orígenes filosóficos de Adorno y que es una de las matrices de la dialéctica negativa, esto es, destacar el abismo que se abre entre el concepto y la cosa, considerar que los conceptos, en la misma medida en que están cargados de experiencias históricas en sus vínculos con la cosa, también sepultan y esconden posibles experiencias alternativas en su relación con ella.

\section{V}

Adorno entenderá su concepción negativa de la dialéctica no solo como un modo de aproximarse a la realidad no determinado exclusivamente por la identidad, sino también como una manera de pensar la utopía como "tierra de nadie». Con esa concepción negativa de la dialéctica pretenderá trascender tanto sus hipóstasis idealistas como las materialistas. Ese concepto utópico de «tierra de nadie» (que equiparó al trascendental kantiano) constituía una esfera no meramente lógico-formal - porque se refiere a la posibilidad del conocimiento de objetos- y tampoco podía entenderse como una esfera sustantiva, pues no presupone ningún contenido: «Se refiere tan solo a la posibilidad de tener tal contenido" ( $\mathrm{Ng} \mathrm{IV,} \mathrm{4,} \mathrm{40).} \mathrm{Esa} \mathrm{idea} \mathrm{de}$ «tierra de nadie» es una de las claves de la lectura que Adorno hace de Kant, pues vio en su filosofía un contrapeso tanto al pensamiento de Hegel como al marxismo dominante, pues uno de sus objetivos siempre fue criticar la idea de totalidad: «El todo es lo no verdadero", como solía decir. Y, en este sentido, para él -como para Kant- la humanidad no radica tanto en la colectividad como en los individuos. En ellos, y en ese llamamiento kantiano al sapere aude, al pensar por uno mismo, en la idea de un sujeto crítico y reflexivo, encontraba la posibilidad de resistir el espíritu del tiempo, el avance hacia un mundo cada vez más administrado y hacia la fuerza

20 Kant, I. Op cit., A556/B884. 
coactiva de la colectividad en la que las diferencias entre los individuos se borraban paulatinamente ${ }^{21}$.

La idea de sujeto moderno, capaz de autodeterminarse, que la filosofía de Kant representó de manera modélica, será clave para Adorno. Ese sujeto que «avanza penosamente tras su propia cosificación» (GSA 7, 179) necesita de la confianza en sí mismo, del esfuerzo por intentar "concentrase o integrase en la propia consciencia»" Y, para él, eso significaba que el individuo fuera capaz de poner las bases para superar una existencia en la que prima lo colectivo. Esas ideas de sujeto y de razón las entiende como cifra de la verdadera humanidad, como unión de individuos libres; como «tierra de nadie» y, al mismo tiempo, de todos, como escribió $\mathrm{Kant}^{23}$. La idea kantiana de lo trascendental equivale a una universalidad que no es solo ilusoria, sino también real; es decir, como el ámbito para pensar que las cosas podrían ser de otro modo, es la cifra de la reconciliación:

La razón en cuanto yo trascendental supraindividual contiene en sí la idea de una libre convivencia entre los individuos en la que estos se organizan como sujeto universal y superan el conflicto entre la razón pura y empírica en la consciente solidaridad del todo. Ella representa la idea de la verdadera universalidad, la utopía (GSA 5, 102).

Pero en Dialéctica de la Ilustración Adorno y Horkheimer denunciaron otra arista de la razón, entendida como facultad mecánica -como ratio-, como instancia del pensamiento calculador, que convierte el objeto en material de dominio. Una arista que rebaja el concepto burgués de humanidad no solo a instancia abstracta, sino totalitaria. Para ellos, la filosofía de Kant también encarnaba de forma paradigmática esa otra cara de la razón. Ni Adorno ni el resto de los teóricos críticos positivizaron la utopía, pues su punto de partida era lo que no debería ser frente a lo que debiera ser. Sin embargo, en algunos de sus textos se dibuja la idea de utopía como representación de «una asociación de sujetos libres y autónomos en virtud de la posibilidad de una vida mejor y, con ello, la crítica a las relaciones sociales naturalizadas» (GSA 8, p. 306 y ss.). Es decir, se planteaban el establecimiento de una sociedad racional que correspondiera a un concepto distinto de humanidad. En esas ideas se plasma la necesidad de «recuperar la naturaleza en el sujeto», la reconciliación de éste con lo distinto, con el no-yo. El recuerdo de la naturaleza en el sujeto - uno

${ }_{21}$ Para Horkheimer, el pensamiento de Kant, mucho más que el de los fundadores del socialismo, encarnaba la posibilidad de atenuar la contradicción entre la libertad y la justicia, entre lo individual y lo colectivo: «El socialismo no significa la realización cumplida del individuo... [pero] el individualismo que no es capaz de transformarse en justicia social cae en el peligro del totalitarismo. La unidad de libertad y justicia pertenece al núcleo de la filosofía kantiana», Horkheimer, M. Op. cit., vol. 7, pp. 171-172.

${ }^{22}$ Adorno, Th.W. Philosophische Terminologie II, p. 206, Frankfurt am Main, Suhrkamp, 1974.

23 «La razón humana, que no reconoce más juez que a la razón humana [es aquel espacio] donde todos tienen voz», Kant, I. Op. cit., A758 /B786. 
de los temas centrales de Dialéctica de la Ilustración- era un contrapeso necesario a una racionalidad dominadora incapaz de garantizar la finalidad para la que había surgido: la autoconservación del sujeto. Articular la anamnesis de la naturaleza en el sujeto como impulso material sobre el que asentar la posibilidad de la reconciliación entre los sujetos y entre éstos y un mundo (que han convertido en objeto de dominio) determinará su formulación de una dialéctica negativa como intento de desbloquear las antinomias kantianas, radicalizándolas. Una dialéctica que, en lugar de cerrar las contradicciones, las mantiene abiertas.

Esa idea acerca de la posibilidad de pensar en una humanidad distinta se vincula con sus reflexiones sobre el principio del intercambio que vertebra el desarrollo civilizatorio. El interés que Adorno mostró desde joven por la filosofía le llevó a considerar la economía política no tanto como una ciencia, sino como una crítica global a la reproducción de la vida ${ }^{24}$. El principio del intercambio, que ha marcado el devenir histórico y social, constituía una abstracción que convertía el trabajo y las capacidades de los sujetos en mercancías. Bajo ese principio no solo se intercambia lo desigual, sino que se generan antagonismos. Ese principio no solo equipara y nivela a los seres humanos de manera abstracta, sino que determina un tipo de economía que configura tanto la vida social como la de los individuos, pues, para Adorno, el proceso de abstracción transfigurado por la filosofía se desarrolla en la sociedad del intercambio real. No solo critica el principio de intercambio (que reduce el trabajo humano al concepto general abstracto de tiempo medio de trabajo social) y destaca su carácter contingente, sino que también piensa en la posibilidad de otro que sea «libre y justo» (GSA 6, 150). En suma, en una humanidad que pudiera reconciliar lo universal y lo particular, lo colectivo y lo individual; una humanidad capaz de producir una asociación de individuos libres y plurales que frenen sus ansias de dominio y se abran a lo otro del sujeto ${ }^{25}$.

\section{VI}

En Dialéctica de la Ilustración Adorno y Horkheimer no solo tuvieron presente la filosofía kantiana para presentar la deriva de una ilustración devenida en dominio, sino también para sostener que ésta seguía siendo un proyecto emancipador. En «Elementos del antisemitismo» abordaron el problema del rechazo a lo diferente, al otro, ejemplificándolo en el odio hacia los judíos. Y lo hicieron a través de siete tesis en forma de constelaciones (y que es una de las primeras aproximaciones a ese modelo constelativo que Adorno plasmará en su Dialéctica negativa) que se ocupaban de esa cuestión desde puntos de vistas culturales, económicos o religiosos. Una

${ }^{24}$ Cfr. Zamora, J.A. «Th.W. Adorno. Crítica inmanente al capitalismo», en Melancolía y verdad, J. Muñoz (ed.), Madrid, Biblioteca Nueva, 2011.

${ }_{25}$ Sobre la idea de utopía en Adorno, $c f r$. Demirovic, A. «Libertad y humanidad». Indaga, n. ${ }^{\circ}$ 2, Publidisa, 2004, p. 5 y ss. También, Demirovic, A. Der nonkonformistische Intellektuelle. Die Entwicklung der Kritischen Theorie zur Frankfurter Schule, Frankfurt am Main, Suhrkamp, 1999. 
de las perspectivas desde las que estudian el fenómeno antisemita es una teoría del conocimiento (tesis VI) que no llegaron a desarrollar posteriormente ${ }^{26}$. Ahí trataban de mostrar que el conocimiento consistía en una proyección de vivencias, deseos, miedos, fantasías o preferencias con las que el sujeto ordena y da sentido al mundo en el que vive: «Toda percepción es una proyección», basada en juicios previos, por medio de la cual se lucha por la vida y la autoconservación. Y en ese proceso, con el que el sujeto da unidad a la diversidad, se constituye el yo en la medida «en que aprende a dar unidad sintética no solo a las impresiones externas, sino también a las internas» (GSA 3, 214). Esa idea, que fundamentan tanto en Kant como en Freud, señala que nuestros conocimientos se fundan en pre-juicios, que son la posibilidad y las líneas que orientan el conocimiento ${ }^{27}$. Como escribió Horkheimer: «Los instintos nativos son tan básicos en la jungla de la civilización, como en la selva primigenia: sin la maquinaria de los prejuicios nadie podría cruzar la calle [...] si no quiere que le pasen unas ruedas por encima $»^{28}$. Éstos se pueden convertir en un juicio fundado (prejuicios positivos) cuando pasan por el tamiz de la razón, pero si no son cuestionados críticamente derivan en juicios sin fundamento (prejuicios negativos). Es decir, que nuestra manera de conocer se basa en la interacción entre el sujeto y el mundo, y que el modo en que le damos sentido a éste viene dado por nuestras proyecciones. Estas pueden darse «bajo control» o convertirse en «falsas proyecciones»: "Entre lo interno y lo externo, hay un abismo que el sujeto debe llenar con propio riesgo» (GSA 3, 214). El conocimiento se genera, pues, «en un entramado de prejuicios, intuiciones, inervaciones, autocorrecciones y exageraciones; en suma, en la experiencia intensa y fundada, que no es en manera alguna transparente en todas sus direcciones» (GSA 4, 90).

El conocimiento no se halla libre de proyecciones, pero solo en la medida en que éstas son valoradas desde una actitud crítica y autocrítica adquieren rasgos no destructivos y se alcanza consciencia moral, y con ello «la capacidad de hacer propio el verdadero interés de los demás» (GSA 3, 240). En esta tesis sobre el antisemitismo discuten elementos que están presentes en la teoría del conocimiento kantiana. Inciden en que la razón siempre piensa desde un material sensible, pero cuestionan la idea kantiana de salvar el abismo entre el sujeto y el objeto desde la proyección de una subjetividad abstracta. También asumen del psicoanálisis freudiano la necesidad de controlar y sacar a la luz los elementos inconscientes y afectivos que forman parte del pensamiento. Esos vínculos que establecieron entre Kant y Freud podrían resumirse en esta sentencia de Adorno: «El psicoanálisis reduce a condicionamientos psicológicos lo que Kant apriorizó como imponente majestad» (GSA 6, 231). El nexo

${ }^{26}$ Para un análisis de esa teoría del conocimiento esbozada por Adorno y Horkheimer en Dialéctica de la Ilustración, cfr. Gandler, S. Fragmentos de Frankfurt. Ensayos sobre la Teoría Critica, México, Siglo XXI, 2009.

${ }_{27}$ Sobre la influencia de Kant y Freud en el pensamiento de Adorno, $c f r$. Whiтевоoк, J. "Whitebook Objects: on Adornos Kant-Freud Interpretation», p. 51 y ss., en Hunn, Th. (ed.) The Cambridge Companion to Adorno, Cambridge University Press, 2004.

${ }^{28}$ Horkheimer, M. Op. cit., vol. 8, p. 195. 
entre las ideas de Kant y Freud se encontraba ya tanto en el escrito de habilitación de Adorno como en la tesis doctoral de Horkheimer, en la que sostenía que, a partir de la filosofía kantiana, había que ahondar en la «originaria escisión de la persona racional como conjunción de voluntad y conocimiento $»^{29}$.

Ahondar en esa escisión, reconocerla como un producto necesario del devenir civilizatorio, al tiempo que se pretende mostrar su carácter histórico y, por tanto, revocable, hace que Adorno y Horkheimer piensen también en la doctrina kantiana del esquematismo como un elemento clave en la construcción de sus pensamientos. En el capítulo sobre «la industria cultural» de Dialéctica de la Ilustración, sus autores interpretan esa doctrina de manera original, a tenor del peso que consideraban que la cultura imperante jugaba en el desarrollo de la consciencia de los individuos ${ }^{30}$.

Si los esquemas de los que trató Kant constituían la condición de posibilidad del conocer, pues eran el puente que proporcionaba homogeneidad entre el concepto y la intuición, entre el entendimiento y la sensibilidad, Adorno trata en sus textos de superar el carácter mediador de los esquemas y, con ello, el «bloque» kantiano, interpretando la mediación sintética de la que da cuenta la Crítica de la razón pura no «por» el esquema que homogeniza, sino «a través» de la intuición. Y, en este caso, no a través de la intuición pura, sino de las «intuiciones empíricas»; esto es, a través del ámbito de lo material y lo sensible. Por eso destacó que el entendimiento y las categorías estaban ya cargadas de sensibilidad proyectiva, del mismo modo que el carácter formal del tiempo que organizaba las intuiciones estaba lleno de sedimentos históricos. De ese modo, trató de quebrar la distinción kantiana entre el conocer y el pensar, la secreta raíz común entre el ser y el pensar, que desplaza ahora al ámbito de la praxis, la historia, la sociedad. Y así, también, pretendía desvelar el carácter de la actividad sintética del pensamiento dentro del ámbito material en el que están insertos los sujetos, en los que opera la actividad esquematizadora que organiza la experiencia.

${ }^{29}$ Horkheimer, M. Op. cit., vol. 2, p. 146.

30 Para ellos, el esquematismo del que Kant hablaba como puente que permitía la homogeneidad entre las categorías y lo sensible y que consideraba «un arte oculto en lo profundo en el alma humana» parecía haber sido desvelado por "Hollywood», entendido éste como símbolo de la industria cultural y de sus productos, como emblema de la ideología del presente: «Para el consumidor no hay nada por clasificar que no haya sido anticipado por el esquematismo de la producción [...] cíclicamente se mantienen los tipos de canciones de moda, de estrellas y operetas como entidades invariables [...] la breve sucesión de intervalos que ha resultado eficaz en una canción de éxito, el fracaso pasajero del héroe [...] son, como todos los detalles, clichés hechos parar usar a placer aquí y allí, enteramente definidos cada vez por el objetivo que se le asigna en el esquema» (GSA 3, 146). 
Adorno, como se desprende de sus clases sobre la Crítica de la razón práctica, hace una lectura de la moral kantiana diferente a la que se encuentra en el «Excursus sobre Juliette» de Dialéctica de la Ilustración (basada en La fundamentación de la metafísica de las costumbres, en la que se ponían en paralelo las ideas morales de Kant, Sade y Nietzsche). Sus reflexiones acerca de la ética kantiana se encuentran difuminadas por toda su obra ${ }^{31}$. Para él, la moral kantiana constituye «un golpe de fuerza» contra lo que planteaba la Crítica de la razón pura. Consideraba que la pretensión kantiana de establecer una ética que trascendiera el ámbito de la experiencia constituía un intento de introducir la moralidad en el mundo que era, a un tiempo, tan sublime como paradójica. Sublime, porque no abandonaba la idea de humanidad al mundo actualmente constituido ${ }^{32}$, porque no dejaba que la razón se achatara en mero entendimiento, en pensamiento instrumental. Por eso, «su mayor atrevimiento" fue hablar de la espontaneidad del sujeto como "cosa en sí misma» y de la posibilidad que tenía para introducir la libertad en el mundo fenoménico. Pero también era paradójica por su exceso de teoricismo, porque la libertad quedaba enmarcada en una racionalidad alejada de lo fáctico, porque su inconmensurabilidad la hacía incompatible con la empiria: «La total racionalidad de la voluntad la convierte en irracional [...] al transformar la acción en puro espíritu, se sirve de éste como sucedáneo de la acción» (GSA 6,236). Pero esa moral también era paradójica por quedar incluida «en la causalidad del mundo de las apariencias, incompatible con el concepto kantiano de libertad» (GSA 6, 230). Adorno destacó que lo sublime y paradójico de la Crítica de la razón práctica consistía en que, a diferencia de la primera Crítica, la eliminación de los elementos materiales es mucho más amplia, pues la razón práctica se hace independiente de la realidad empírica. Y aunque aquella solo procede de la representación subjetiva, yendo más allá del formalismo de la Crítica de la razón pura llega «a representaciones como las de una humanidad

${ }^{31}$ Fueron objeto de sus lecciones del año 1963. Cfr. Adorno, Th.W. Probleme der Moralphilosophe, Nachgelassene Schriften IV 10, Frankfurt am Main, Suhrkamp. Sobre la relación entre la ética de Kant y la de Adorno, cfr. Méndez-Burguillos, M. Zweckmässigkei und Auntonomie, Frankfurt am Main, Berlin, Bern, New York, Paris, Wien, Peter Lang, 1996 y Kohlmann, U. Dialektik der Moral. Untersuchungen zur Moralphilosphie Adornos, Lüneburg, Zu Klampen, 1997, p. 19 y ss. Ya la ética kantiana fue objeto de análisis por parte de Adorno y Horkheimer en el «Excursus sobre Juliette» de la Dialéctica de la Ilustración y en algunos de sus pasajes llegaron a equiparar la apatía de la ley moral kantiana y su reprobación del entusiasmo respecto a cualquier sentimiento e inclinación con las doctrinas de Sade. Una idea que en Kant aparejaba una inquebrantable confianza en la mayoría de edad propia de la Ilustración, para salvar la posibilidad de la razón práctica, y que podía ser compatible con una Ilustración irreflexiva que había hecho suya la bandera de mantener el estado de cosas existente.

32 «Los postulados de la razón práctica que trascienden al sujeto: Dios, libertad e inmortalidad, implican una crítica [...] de la pura razón subjetiva. [El imperativo categórico] ni siquiera podría ser pensado sin esos postulados, aunque Kant asevere lo contrario: sin esperanza no hay ningún bien», (GSA 6, 272). 
ordenada de manera justa que no se podría concebir en absoluto si se mantuviera en aquella puridad de los hechos de manera tan inmediata como está en el programa kantiano» (Ng IV, 4, 262).

Se trata de un pensamiento sublime que se revela paradójico, precisamente, por pretender saltar al ámbito de lo empírico y material. Según Adorno, estas tensiones hacen de Kant un pensador melancólico, pues los postulados sobre los que se funda la ley moral -a diferencia de las categorías del entendimiento- no pueden cumplir sus pretensiones en la experiencia. En Kant hay, afirma, un cierto escepticismo sobre su propio mundo inteligible (GSA 6, 383). Sin embargo, su esfuerzo por «la salvación de la esfera de lo inteligible [...] intenta intervenir en la misma dialéctica de la Ilustración, allí donde ésta termina eliminando la razón misma» (GSA $6,377)$. Por medio de esa esfera cabría pensar en un ámbito de lo posible diferente a lo que existe. A pesar de que Kant trató de salvar el ámbito de lo inteligible, el establecimiento de un sólido bloque entre éste y lo fenoménico, la separación entre la voluntad y el conocimiento, conduce a que el conocer se vuelva contra el pensar, a la consagración de una razón cada vez más instrumentalizada, que deja de apuntar a los sentidos. El empeño de Adorno y de la Teoría crítica es reflexionar sobre ese proceso, para que el conocimiento no se escinda del pensar.

Para Adorno, la razón práctica kantiana se mueve entre contradicciones que dan cuenta de las tensiones reales sobre las que se eleva. El empeño de Kant por concebir la libertad como un factum le impide pensar acerca de su carácter histórico. Para él, eso constituye el momento ideológico de la Crítica de la razón práctica, pues el mundo se presenta como un mundo humano sin aún serlo, pues «somos heterónomos y vivimos en un mundo de no libertad». Pero, además, en Kant la libertad «se revela como un concepto vano e imposible, una vez relegado a propiedad del sujeto atemporal» (GSA 6, 250). Destacó que el empeño kantiano por defender la autonomía y la independencia de la ley moral le hizo olvidar la conexión de todos los sujetos, pues «solo teniendo en cuenta la alteridad, el no yo, puede juzgarse sobre lo que decide y es, a la vez, lo decisivo en el yo: su independencia y autonomía» (GSA 6, 222). En este sentido, para Adorno, Kant -aunque de manera excesivamente voluntarista- no perdió de vista el auténtico problema de la Ilustración respecto a lo que hacía que un sujeto fuese tal (más allá de sus determinaciones materiales). Esto es, la posibilidad de su constitución autónoma y libre.

En su exposición de la ética kantiana, mantiene algunas ideas que ya había desarrollado en sus primeros escritos. Así, por ejemplo, sobre el concepto de sujeto trascendental planteaba que Kant elevaba su universalidad a partir de la pluralidad de los sujetos, para luego «autonomizarla como objetividad lógica de la razón» (GSA $6,277)^{33}$. Pero no tiene en cuenta que el sujeto no es algo aislado, que no se pueden

${ }^{33}$ En 1925 Adorno conoció en Italia a A. Sohn-Rethel, con quien desde ese momento comenzó a debatir diferentes cuestiones filosóficas, sobre todo relativas a la abstracción y al sujeto. Como anota Adorno en Dialéctica negativa: «Alfred Sohn-Rethel fue el primero en advertir que [...] en la actividad general y necesaria del espíritu se oculta, inevitablemente, el trabajo social» (GSA 6, 178). Para Sohn-Rethel, la capacidad abstractiva se derivaba de la social, de «abstracción real»; esto 
eliminar sus determinaciones, sus vínculos con el mundo social e histórico. Frente a Kant, insistió en que las intuiciones morales inmediatas eran producto de los imperativos sociales, de la coacción social. Para él, el sujeto trascendental kantiano, tiene en común con la sociedad su carácter de universalidad. Ese sujeto «remite más allá de la mera arbitrariedad de la existencia singular y [...] de la forma condicionada y transitoria que tiene una sociedad en cada estadio determinado [...] en la que ya está implícita verdaderamente la utopía de una sociedad ordenada racionalmente» ( $\mathrm{Ng} I \mathrm{~V}, 4,262)$. Pero del mismo modo, en ese sujeto se contiene la no verdad de la sociedad sobre la que se construye el individuo: «La forma interiorizada e hipostasiada del dominio humano sobre la naturaleza, que siempre ha tenido lugar mediante la eliminación de las cualidades, lleva las diferencias cualitativas a formas cuantitativas» (ibid.).

Adorno sostuvo que la idea de libertad entendida como «dato» conlleva el peligro de legitimar lo existente, o que cuando Kant entiende la moralidad como ley no solo muestra «su pusilánime horror burgués por la anarquía» (GSA 6, 248), sino que impide que «se la tome tan poco en serio como siempre lo ha hecho su clase» (ibid.). Por eso propone comprender la libertad desde negaciones determinadas, «a partir de la figura concreta de lo que se le opone» (GSA 6, 230). Sobre esas ideas sustentó su "ética negativa» como un modo de confrontarse a lo existente, algo de lo que no solo dejó constancia en su Minima moralia o en sus lecciones sobre «Problemas fundamentales de filosofía moral», sino también en su Dialéctica negativa. En esos escritos planteó que no cabe dar con definiciones positivas de los conceptos éticos, como sostiene la tradición filosófica, y se opuso al formalismo kantiano (pues consideraba que las acciones morales no pueden partir de la idea de una buena voluntad), sino que defendió que la acción moral ha de evitar el dolor y el sufrimiento innecesarios, que la ética tiene que atender a aquello que está a «ras del suelo». Esto es, a lo tangible, a lo somático y a lo corpóreo. Algo que le llevará a formular, al modo kantiano, un nuevo imperativo categórico: «Orientar el pensamiento y la acción de modo que Auschwitz no se repita» (GSA 6, 358) ${ }^{34}$. Este imperativo, a diferencia de las distintas formulaciones del imperativo categórico kantiano, no emerge de la mera interioridad, de la autolegislación de la razón, sino que se engarza en la experiencia histórica; expresa su idea de que la moral no sobrevive más que «en el materialismo sin tapujos». Un imperativo que es, pues, expresión de la solidaridad con el dolor.

es, la abstracción del intercambio da lugar a la abstracción de la conciencia. Si Adorno vio en los trabajos de Sohn-Rethel tesis enormemente productivas, Horkheimer, por su parte, las encontró poco dialécticas, como le escribió a Adorno: «Encuentro [...] carente de interés la constante afirmación de Sohn-Rethel de que deben hacerse demostraciones según las cuales ciertas génesis establecidas desde el ser o desde la historia, o del desarrollo del ser del hombre [...] coinciden con el problema de la verdad de la conciencia», Th.W. Adorno/M. Horkheimer, Briefwechsel, vol. 1 (1927-1937) (Gödde, Ch. y Lonitz, H. eds.), Frankfurt am Main, Suhrkamp, 2003, p. 249. Sobre la relación de Adorno con Sohn-Rethel, $c f r$. C. Escuela Cruz, «Técnica, intercambio y mundo administrado. Sobre las posibilidades de emancipación social en Adorno y Sohn-Rethel», en Савот, M. (ed.), Tecnología, violencia, memoria, Barcelona, Anthropos, 2018, pp. 55-71.

34 Sobre la ética negativa de Adorno y su imperativo moral, $c f r$. Schweppenhëusser, G. Ethik nach Auschwitz, Adornos negative Moralphilosophie, Springer, 2011. 
Adorno daba a entender que la ética -como impulso hacia una vida buena y feliz- carecía de cualquier fundamento normativo, que nada garantizaba lo que podría entenderse como «una vida no dañada». Para él, la razón práctica no parecía estar cargada de esperanza; era, más bien, una razón sin esperanza. La praxis moral no dependía solo de un actuar acertado, sino de circunstancias y contextos sobre los que el sujeto carece de poder. Frente a Kant, argumentaba que ningún tipo de certeza moral podía garantizar lo justo de una acción. Al contrario, los principios morales inconmovibles podían ser implacables y conducir a comportamientos injustos:

La voluntad pura no es tanto la disposición al bien, cuanto la disposición a lo atroz [...]. No existe algo así como la seguridad moral [...]. Suponer que pudiera saberse alguna vez, sin lugar a dudas [...] qué es lo bueno, cabría decir que eso mismo es ya el principio del mal (Ng IV, 10, 264-265).

Y, a pesar de ello, piensa que no cabe resignarse ni hacer omisión del deber moral. En su ética materialista, contraria a imperativos formales y a leyes morales inconmovibles, resonaba el eco de la pregunta kantiana: «¿Qué debo hacer?». Consciente de las pocas fuerzas con las que cuenta el sujeto, pese a todos los condicionantes a los que éste se hallaba encadenado, sostenía que la esperanza por prevalecer en lo justo debía entretejerse en la acción.

Frente a la idea kantiana de que el imperativo categórico debía prescindir de toda inclinación sensible y de todo entusiasmo e instalarse en un ámbito atemporal, y frente a la conocida segunda formulación de ese imperativo: «Actúa de tal modo que uses a la humanidad, tanto en tu persona, como en la de cualquier otro, siempre como un fin y no solamente como un medio" ${ }^{35}$. Adorno no lo interpretó como el sometimiento de nuestras acciones a una ley moral inconmovible, sino en el sentido de que en toda acción moral se tuviesen en cuenta de manera concreta los intereses de los sujetos implicados en ellas: «Podríamos decir [...] que en el ámbito moral la universalidad remite a la pluralidad de los sujetos y, en última instancia, a la sociedad» ( $\mathrm{Ng} \mathrm{IV}, 10,367)$. La actuación moral que pretendiera ser justa no consistiría en que el individuo reprimiese sus inclinaciones, sino en que incorporase a su reflexión los intereses de los otros. Trató, pues, de transformar esa ética individual kantiana -que cristalizaba en imperativos formales- en una ética intersubjetiva, que pugnaba, a su vez, por una transformación del mundo social.

\section{VIII}

Sus ideas sobre la ética kantiana se enlazan con las que hace sobre la metafísica. Pero este enlace pretende ir más allá de la demarcación kantiana entre ciencia y metafísica. Para Adorno, la radical escisión kantiana entre razón teórica y práctica, a

1992.

35 Kant, I. Akademieausgabe Gesammmelten Werken, vol. Iv, p. 249. Hildesheim, Olms, 
pesar del primado que le dio a ésta última -inaccesible para el conocimiento-, acaba por revelarse impotente. Consideraba, por el contrario, que ambos tipos de razón no solo no podían entenderse como escindidas, sino que constituían una forma de conducta y apuntaban a un mismo objetivo: la emancipación. Como Kant, mantenía que la filosofía «es la ciencia de la relación de todos los conocimientos con los fines esenciales de la razón humana $\aleph^{36}$. Aun asumiendo que el pensar materialista no debe «irse de mundos inteligibles», supo ver que en el mismo núcleo de la filosofía kantiana, «la salvación de la esfera de lo inteligible [...] trata de intervenir en la misma dialéctica de la ilustración allí donde ésta termina eliminando la razón misma» (GSA $6,377)$. De ahí que su filosofía mostrara continuamente la necesidad de salir de la isla de la verdad que Kant topografió y hacer incursiones en el océano que a cada instante amenazaba con tragarse esa isla ${ }^{37}$. Es decir, que la teoría requiere también de experiencia metafísica (aunque la filosofía actual la considere frecuentemente de modo similar al feo enano de la teología sobre el que escribió Benjamin). Si Kant se había preguntado por la posibilidad de la metafísica como ciencia, Adorno se planteaba si aún era posible la experiencia metafísica. Esa experiencia metafísica que defiende, como parte de una experiencia no mutilada, se opone tanto a la ontología como al positivismo craso. Una experiencia que evite, además, recaer en el idealismo o en el pastoreo del Ser; es decir, que se oponga a que «la crítica al criticismo se haga precrítica» (GSA 6, 70). Consiste, más bien, en un modo de no capitular ante lo dado, en pensar la desesperación, en condenar lo insufrible, en cuestionar la prisión de la inmanencia de la autoconservación que glorifica lo dado.

Para él, esa experiencia debía hacer borrón y cuenta nueva con toda idea anterior de metafísica y reconstruirla «a partir de cero» (GSA 6, 379): «El planteamiento kantiano que presupone la metafísica como disposición natural, se refiere al cómo de un conocimiento dado por necesario y universalmente válido, por más que en realidad apunte a su qué, a su misma posibilidad, y ésta es negada de acuerdo al ideal científico» (ibid.). Y que fuera pensada, además, «desde materiales y categorías de la inmanencia» (GSA 6, 400), y entendida "como constelación legible de lo que existe». Se trata de una "metafísica negativa» que no debía capitular ante lo óntico y centrarse en lo micrológico, en lo pequeño y desastrado, en los intereses materiales de los seres humanos. Pensar si la metafísica era aún posible consistía en «reflexionar la negación de lo finito exigida por la finitud» (GSA 6, 384) y eso supone que lo que se espera no está garantizado y, por tanto, habría que pensar una situación cuya medida es la penuria; una reflexión que considera necesaria, porque

conforme va quedando menos vida, se acentúa para la consciencia la tentación de tomar por revelación del absoluto los restos contados, sorprendentes, que quedan de ella [...]. Si nada prometiera algo trascendente a la vida, tampoco sería posible experimentar nada verdaderamente vivo [...]. Lo trascendente es y no es (ibid.).

\footnotetext{
36 Kant, I. Kritik der reinen Vernunft, A839/B867.

37 Sobre esa isla kantiana de la verdad rodeada por «una ancho y borrascoso océano», $c f r$. Kant, I. Op. cit., A235/B 295.
} 
La metafísica, como Kant expresó, constituye una apariencia necesaria. En consonancia con ello, Adorno sostuvo que «la salvación de la apariencia, objeto de la estética, posee una incomparable importancia en la metafísica» (GSA 6, 386). En 1959, impartió un curso sobre estética donde puso de relieve que el arte auténtico gira en torno a la «no identidad». Es decir, aquello que se resiste a la magia identificadora del concepto, lo que puede abrirse a «experiencias no reglamentadas», a las que se halla sujeto el pensamiento discursivo. Consideraba al arte como un ámbito cognoscitivo en el que lo empírico podría organizarse con criterios diferentes a los del conocimiento habitual y, de ese modo, propiciar un reflexión sobre lo no idéntico $^{38}$. El arte, afirma, conserva aún «la fuerza de la negatividad» (GSA 7, 26), pues podría introducir caos en un mundo que se presenta armónico, porque carece de funcionalidad frente al pragmatismo imperante. Es, a un tiempo, crítica de lo real y promesa de felicidad. Y, en este sentido, es negación determinada de una sociedad determinada, es «antítesis social de la sociedad». Para él, el arte constituye un espacio de denuncia capaz - como la metafísica- de dar expresión al dolor: «¿Qué sería del arte [...] si borrase el recuerdo del sufrimiento acumulado?» (GSA 7, 387).

También la estética de Adorno arranca de la crítica al pensamiento de Kant y al de Hegel, pues, para él, ambos conciben la relación entre forma y contenido respecto a la experiencia estética de manera adialéctica: «El concepto kantiano de algo que agrada por su forma resulta retrógrado [...] y la doctrina hegeliana del contenido es demasiado cruda» (GSA 7, 528). Una y otra no se pueden separar, pues la forma (la estructura lógica de la obra) es contenido sedimentado, y el contenido está atravesado por formas. Entre las tesis más conocidas de su estética se encuentra la de que el arte no es imitación de la naturaleza, sino de su belleza ${ }^{39}$; esto es, de una imagen de naturaleza no sometida a coacción, de una idea que es «cifra de reconciliación» y que corre paralela a su concepción de «no identidad». Pero lo que resulta relevante en estas lecciones es la lectura que hace de la estética kantiana, y que se enlaza con algunas de sus reflexiones acerca de la Crítica de la razón pura, sobre todo la idea de que en Kant se abre un camino dialéctico entre forma y contenido, entre sujeto y objeto, entre lo idéntico y lo no idéntico. Frente al tópico histórico-filosófico de que Kant intentó reducir la estética a categorías subjetivas a través de la síntesis entre formas y contenidos de la intuición, Adorno sostiene que las obras de arte están «en sí mismas altamente calificadas y articuladas» tanto como el sujeto que las experimenta, que también está cargado de experiencias históricas y, por eso, «no puede ser comparado con aquel sujeto trascendental generalísimo». Es decir, que el objeto y el sujeto de la experiencia estética kantiana no se hallan uno frente a otro en la relación trascendental de la apercepción originaria, sino que «ambos caen ya en

${ }^{38}$ Sobre el papel del arte en la filosofía de Adorno, $c f r$. Menke, Ch. Die Souveranität der Kunst: Ästhetische Erfahrung nach Adorno und Derrida, Frankfurt am Main, Suhrkamp, 1991.

39 Sobre el concepto adorniano de «belleza natural», cfr. Figal, G. «Th.W. Adorno. Das Naturschöne als Spekulative Gedanken Figur» en FigaL, G. Kontext philosophischen Ästhetik, Bonn, 1977, p. 56 y ss. 
el mundo constituido, y de esa forma cesa la primacía del sujeto frente al objeto, y los dos momentos se producen el uno al otro de manera recíproca» ( $\mathrm{Ng} I \mathrm{~V}, 3,322)$.

\section{IX}

Sus lecciones de finales de los cincuenta sobre la Critica de la razón pura fueron preparando el terreno para la construcción de una dialéctica negativa. Como afirmó en ellas: «Les he desarrollado a partir de Kant la elaboración de los elementos de un pensamiento dialéctico [y negativo]» $(\mathrm{Ng} I V, 4,352)^{40}$. Allí explicaba que los dualismos que Kant dejó abiertos entre forma y contenido, entre sujeto y objeto, entre ciencia y filosofía, entre razón y entendimiento, no deberían ser liquidados, sino mediados: «La concepción kantiana aún permitía dicotomías como la de forma y contenido, sujeto y objeto, sin que la mediación de los pares opuestos la desconcertará; no advertía la esencia dialéctica de éstas, la contradicción como la implicación de su sentido» (GSA, 6, 140). Destacó en la obra de Kant las mediaciones entre todos esos polos aparentemente opuestos que Hegel trató de superar en una dialéctica que desembocaba en Espíritu absoluto, en tautología, en identidad. En su formulación de la dialéctica contrapuso el pensamiento kantiano tanto a la dialéctica hegeliana como a las versiones imperantes del marxismo, pues consideraba que solo manteniéndose en el marco kantiano, que pivotaba sobre la tensión entre sujeto y objeto, era posible no recaer en la prima philosophia. En su opinión, las tensiones y antinomias de la filosofía kantiana impedían que el pensamiento derivase en identidad y terminase por reducir un polo del conocimiento a otro. Según él, hay algo que se había olvidado de la filosofía kantiana: la idea de que el constitutum no tiene un primado ontológico sobre el constituens, que esos momentos de materia y forma, de sujeto y objeto, están mediados entre sí; que se refieren mutuamente: «En la filosofía kantiana está ya planteado el posterior pensamiento hegeliano de la mediación universal, aunque si bien [Kant] no lo planteó así» (Ng IV, 4, 240). El pensamiento kantiano, como afirmaba Adorno, aún sobrevivía a la decadencia del idealismo en el que había culminado.

Para Adorno, el carácter antinómico de la dialéctica trascendental kantiana expresaba de forma idealista los antagonismos de la realidad histórica, que acababan siendo legitimados en el campo de la teoría. Por ello, la gramática profunda que articulaba los elementos de la conciencia kantiana tendría que buscarse en la realidad histórica y social. Cuando Kant se enfrentaba al carácter antinómico de esa conciencia, afirmaba que éste consistía en «hacer que la razón [...] se fije en los factores que

${ }^{40}$ La dialéctica -como discutían Adorno y Horkheimer en los Protocolos del año 1946exigía poner en cuestión «la pretensión hegeliana de determinar la identidad de ser y pensar. Para ellos, Hegel insertó la razón en la historia y no solo lo hizo estableciendo una teleología que identificaba lo real y lo racional, sino justificando el cúmulo de cadáveres que dejaba la marcha de un proceso histórico ineluctable», cfr. Horkheimer, M. Op. cit., vol. 12, p. 601. 
intervienen en la determinación de sus principios» ${ }^{41}$. Consideró que esos factores eran internos a la propia razón, que trascendían las condiciones espaciotemporales de la experiencia posible. Y en ese sentido, Adorno sostenía que Hegel recogió esa tensión dinámica que Kant situó en el interior de la razón y trató de verterla sobre el mundo histórico a través del trabajo conceptual. Pero mantuvo que la dialéctica hegeliana, capaz de movilizar el pensamiento antinómico de Kant, desembocaba idealistamente en identidad entre ser y pensar. Frente a ésta destacó que la dialéctica de Marx supo poner de relieve el núcleo terrenal de las ideas, que el movimiento de éstas se ralentizaba o aceleraba en la medida en que su origen y su forma de proceder dependían de sujetos concretos sometidos a las condiciones materiales en las que se desarrolla su vida. Sin embargo, aunque su pensamiento se fue desenvolviendo también desde Marx, rechazó la idea de que el marxismo pudiese ser entendido no solo como una ciencia, sino como una filosofía que tuviera respuestas para todas las preguntas que pudieran formulársele. Esa opinión la compartía con Horkheimer, para quien «el marxismo como teoría crítica de la sociedad no puede ser hipostasiado, ni ser tampoco simplemente filosofía ${ }^{42}$.

En el segundo semestre de 1958 impartió unas lecciones de introducción a la dialéctica ${ }^{43}$. Las ideas que expone en esas lecciones, y que encontrarán su culminación en la Dialéctica negativa, habían comenzado a desarrollarse en las discusiones que mantuvo con Horkheimer en los años treinta ${ }^{44}$. En esas lecciones esboza la idea de una dialéctica que no desembocara en filosofía primera, en ontología, ni acabase en la identidad de sujeto y objeto, de concepto y cosa, de pensar y ser. Si bien se centró en la dialéctica hegeliana y en la Fenomenología del espiritu desde una perspectiva crítica, el pensamiento de Kant se hallaba en su trasfondo. Una mirada atenta tanto a estas lecciones como a la Dialéctica negativa revelan, más bien, lo que Adorno no entiende por dialéctica que lo que comprende bajo ella. Su forma de exponer el significado de la dialéctica es tan «dialéctica» como «negativa».

2010

${ }^{41}$ Kant, I. Op. cit., A524/ B552.

${ }_{42}$ M. Horkheimer Archiv, VI. 5. 131.

43 Cfr. Adorno, Th.W. Einführung in die Dialektik (Ch. Ziermann, ed), Suhrkamp, Berlin,

${ }^{44}$ La idea de elaborar un pensamiento dialéctico se recoge en Horkheimer, Idee, Aktivität und Program des Institut für Sozialforschung, Horkheimer, M. Op. cit., p. 156 y ss. Pero también en los protocolos de discusión del Instituto de finales de los años treinta, en los que se puede ver el empeño por parte de Adorno de elaborar, junto a Horkheimer, una «lógica dialéctica». Se planteaban si la dialéctica materialista podía entenderse como una forma de conocimiento. Esas discusiones giraron en torno a dos cuestiones centrales: de una parte, si era posible establecer un concepto de verdad, tras excluir la posibilidad de identidad entre sujeto y objeto, y, de otra, cómo concebir una dialéctica que no se oriente por las ideas de "totalidad» y «sistema». En esas conversaciones, Horkheimer hablaba de la necesidad de pensar una "dialéctica abierta", así como de la idea de que el concepto de "hecho" sería el de lo no idéntico. Por su parte, Adorno indicaba que el pensar postulaba siempre el no pensar, que ésa sería la consciencia de la no identidad, que todo conocer indica siempre lo que se halla fuera de la inmanencia de la conciencia. Esto es, que la no identidad debe entenderse como un elemento crítico, desde el que se puede establecer que el contenido del concepto no es la cosa, que ésta no se deja reducir totalmente a objeto. 
Como afirmaba en sus clases, Hegel extrajo las consecuencias del pensamiento kantiano, pues «en realidad, la dialéctica [...] es la filosofía kantiana llevada a su autocomprensión» (Ng IV, 2, 27) ${ }^{45}$. Hegel, explica, ahondó en una idea en la que Kant no profundizó. Si éste pensó en los a priori como elementos inmutables y convirtió el tiempo -como se deriva de la doctrina del esquematismo- en el organon de la verdad, sin embargo sobrevoló la historia y no penetró en lo que es una exigencia del pensamiento dialéctico: la idea de que la verdad posee un núcleo temporal. Tampoco Kant había sido capaz de desarrollar el tema de la contradicción, que solo esbozó en la "Dialéctica trascendental», donde sostuvo que las categorías con las que organizamos la experiencia se desbocan cuando desde ellas se pretende afirmar lo absoluto. Hegel, por el contario, sí elevó la contradicción a la consciencia e insertó el pensamiento en el orden temporal.

Adorno quiso mostrar que en Kant hay una dialéctica in nuce que muestra la inevitabilidad de las contradicciones. Pero la solución que ofrece para salir de ellas es establecer una diferencia entre el ámbito fenoménico y el nouménico, que se rigen por normas diferentes. Sin embargo, la dialéctica de Hegel trató de romper con esas oposiciones no mediadas entre forma y contenido, abstracto y concreto, finito e infinito, a priori y a posteriori. Pero acabó por equiparar la negación de la negación con la positividad que culmina en "Espíritu absoluto». Frente a esa positividad el modo dialéctico que Adorno defiende se basa en «la negación determinada, en la crítica» (GSA 6, 161). Para él, lo rescatable de la formulación dialéctica hegeliana es su carácter no estático, el poner la razón contra sí misma, el confrontarse con la experiencia, con la historia, así como su potencia para corregir el orden conceptual a través de los objetos. Pero le critica a Hegel su voluntad sistematizadora, el que al final del proceso dialéctico sujeto y objeto acaben por identificarse. También criticará las versiones materialistas de la dialéctica, no solo su versión abreviada y dogmática devenida «diamat», que desemboca en ontología, sino la versión dialéctica marxiana, al menos del modo en que se expresa en el epílogo a la segunda edición de $E l$ Capital, en la que la dialéctica aparece no solo como un modo de exposición, sino también de investigación; como un método para exponer la cosa y como un método para dar con la cosa misma ${ }^{46}$. Esta versión materialista de la dialéctica le resulta próxima a la idealista, pues en ella lo individual solía quedar relegado a un segundo plano desde categorías totalizadoras ${ }^{47}$. Para él, ni en la versión hegeliana ni en la materialista de la dialéctica «se ha extraído con toda coherencia que el pensar

${ }^{45}$ M. Horkheimer también sostenía esta tesis: «La aplicación consecuente de la crítica kantiana lleva [...] a la afirmación del método dialéctico», Horkheimer, M. Op. cit., 3, p. 91.

${ }^{46}$ Cfr. Ng IV, 2, 14.

${ }^{47}$ Como ha señalado A. Schmidt, el materialismo de Adorno desconfiaba de la concepción marxista según la cual los elementos superestructurales podrían derivarse (de modo más o menos mediado) de la esfera de las relaciones económicas. Para él, por el contrario, la génesis y la función de los fenómenos culturales no agotaba su contenido de verdad, Schmidt, A. «Begriff des Materialismus bei Adorno", en von Friedeburg, L. y Habermas, J. (eds.), Adorno Konferez, Frankfurt am Main, 1983, p. 26. 
dialéctico en general se ajusta a un estado negativo del mundo y trata de llamar por su propio nombre este estado negativo» (Ng IV, 2, 106).

Profundizará en la idea de que la dialéctica no es un mero esquema mecánico, que todo no debe ser interpretado como contradicción, pues eso indicaría, en última instancia, que el mundo es totalmente racional. Sería, más bien, una forma de conducirse (para la que no caben recetas) que trata de deshacer las esferas separadas del pensar, el querer y el sentir. Consistiría, más bien, en el esfuerzo por pensar los límites de la razón, por enfrentarla contra sí misma. Piensa que la dialéctica consiste en tratar de comprender que hay algo que se sustrae a la racionalidad: la negatividad, el dolor, el sufrimiento. En este sentido, es un pensar capaz de abrirse a lo diferente a la razón, sin identificarlo y manteniendo la permanencia de la crítica. Pensaba que algo de eso se contiene en la Crítica de la razón pura, «pues si todo conocimiento no fuera más que mera forma y, por tanto [...], si todo se agotara en el sujeto, entonces el conocimiento no sería verdaderamente nada más que una única y gigantesca tautología» (Ng IV, 4, 105). Para Adorno, hay una especie de diferencia ontológica en Kant, entre el puro ser y los entes, pues el ser solo se da referido a los entes: "Los entes están constituidos por el ser, y al ser puro solo le corresponde verdad solo cuando se refiere a los entes» (Ng IV, 4, 135). Lo fáctico está mediado por las formas (sin ellas sería indeterminado); pero tampoco las formas son válidas en sí mismas: «En este sentido se podría decir que el motivo de la dialéctica está contenido ya [...] en la propia teoría de Kant [...] en el sentido de un dualismo craso entre forma y contenido" (ibid.).

Ese modelo de dialéctica quedó cifrado por Adorno en la idea de «no identidad ${ }^{48}$, una idea que tiene un claro anclaje en el concepto kantiano de «cosa en sí $^{49}$, como un recordatorio de que no todo se agota en la consciencia subjetiva ${ }^{50}$. Lo no idéntico como límite discurre en paralelo a los límites de la razón que Kant estableció en su primera Crítica. Pensar la no identidad es el eje sobre el que discurre la dialéctica negativa de Adorno. Esto es, pensar lo que no es pensamiento ${ }^{51}$, que los conceptos no son capaces de aprehender lo que cae bajo ellos. Es pensar que la razón es injusta «respecto a aquello que no es la razón misma». Eso no idéntico

48 Sobre el concepto de no identidad en Adorno, $c f r$. Thyen, A. Negative Dialektik und Erfahrung, Frankfurt am Main, 1989.

${ }_{49}$ Como ha sostenido Tiedemann, «Adorno interpreta la cosa en sí, de la que Kant no quiere prescindir, como lugarteniente de lo no idéntico, gracias a lo cual, se hace estallar la falsedad idealista originaria de reducir todo a su constitución subjetiva» $(\mathrm{Ng} I V, 4,423)$.

50 Es posible que tratara de eludir el "concepto de cosa en sí» para que no se confundiese con la interpretación que hizo de ella el neokantismo, en concreto $\mathrm{H}$. Cohen, quien la entendía como una especie de tarea infinita capaz de desvelarse en objeto de conocimiento.

51 Como seńala Utte Guzzoni, la consciencia de la no identidad es posible porque en la cosa hay algo que se resiste a ser encerrado en el concepto, y que estriba en tres elementos fundamentales: la particularidad de cada cosa, que la hace diferente a cualquier otra; el contexto en el que cada objeto se vincula a otro; y el carácter histórico de la cosa, ante la que el proceder conceptual parece cegarse, Guzzoni, U. Identität oder nicht. Zur kritischen Theorie der Ontologie, München, 1981, p. 109 y ss. 
sería el índice de lo que de falso hay en la identidad. Es su límite crítico ${ }^{52}$. Implica plantear que lo que piensa el sujeto es diferente a él y reconocer que la cosa nunca es idéntica a lo conceptuado por el sujeto. Enfrentar lo idéntico del concepto con lo no idéntico que éste encierra es la propuesta del modelo de dialéctica adorniana. Y eso supone un cierto retorno a Kant, no solo por mantener el rechazo a la ontología ${ }^{53}$, sino también por defender los límites de la razón y por mantener abierta la tensión entre el sujeto y el objeto: «El lugar específico de la filosofía -afirmó- es la dialéctica sujeto-objeto» (GSA, 283). Y aunque en pocos momentos es explícito con la necesidad de corregir, a través de la filosofía kantiana, tanto la versión idealista como la materialista de la dialéctica, pensaba que los problemas filosóficos de la dialéctica estaban mejor identificados en la obra de Kant, pues «en la Crítica de la razón pura está planteada objetivamente toda la cuestión de la dialéctica, la cuestión de la relación entre identidad y no identidad» (Ng IV, 4, 106).

Adorno radicaliza las antinomias kantianas cuando elabora su proyecto de una dialéctica negativa. Su materialismo le llevó a realizar un "giro copernicano" sobre el giro copernicano de la filosofía kantiana, lo que denominó pensar la intentio oblicua de la intentio oblicua, que pone de relieve el carácter derivado de la subjetividad, los aspectos condicionados de lo condicionante. El mecanismo subjetivo que preforma los hechos se vincula a la objetividad heterónoma del sujeto. Con ese doble giro copernicano trata, pues, de mostrar que las formas del pensamiento derivan del objeto. Como afirmaba en sus clases: en Kant la objetividad misma no tiene un carácter entitativo, «en cierto modo sólo existe en el sujeto [...] es la figura subjetiva de la identidad de sujeto y objeto, mientras que en Hegel esta identidad [...] debe tomarse literalmente en serio ${ }^{54}$. Ese carácter no entitativo y subjetivo de la identidad le lleva a subrayar, precisamente, como ese segundo giro la mediación de sujeto y objeto.

La dialéctica de Adorno pondrá de relieve, como postulaba Kant, que el sujeto no es eliminable del ámbito cognoscitivo. Pero, frente a él, subrayó la prioridad del objeto en el conocimiento; esto es, que «el sujeto es el cómo, nunca el qué» (GSA 10.2, 753), que el sujeto no puede escapar de sus componentes objetuales físico-psíquicas, ni de sus determinaciones sociales. Pero frente al materialismo vulgar o el positivismo, destacó que el objeto es más que mera facticidad. Pensó no solo que el objeto no se agota en lo que de él aprehende el sujeto, sino que el sujeto, cargado de objetualidad, tampoco se diluye en ésta. De ahí que sea imprescindible

52 La no identidad solo puede ser entendida en la filosofía de Adorno como límite crítico de la identidad, pero de ninguna manera como lo otro de lo idéntico. No es su par contradictorio, y solo puede ser pensado en relación dialéctica con lo idéntico. No identidad, como señaló Schnädelbach, no es en Adorno un concepto, «sino solo el símbolo de un concepto, el lugar vacío para un concepto, o, más bien [...] una cifra», SchnÄNdelbach, H. «Dialektik als Vernunfkritik. Zur Konstruktion des Rationalen bei Adorno", en von Friedeburg, L. y Habermas, J. (eds.), Adorno-Konferez, Frankfurt am Main, 1983, p. 66 y ss.

53 Kant, I. Op. cit., A245/B303.

54 Adorno, Th.W. Philosophische Terminologie II, p. 308. 
la autorreflexión, la «reflexión subjetiva y sobre el sujeto». Es en esa idea desde donde se sostiene el papel de la crítica, en aquello que la rebasa, en los instintos, en los sentidos, en el ámbito de lo mimético, en lo corporal. En Adorno, la crítica no se apoya en elementos normativos, sino en el esfuerzo por convertir la experiencia de la impotencia de los sujetos en potencia teórica y práctica. Ésa es una de las claves para entender Dialéctica negativa. Asumió la idea, que se encuentra en la Crítica de la razón pura, de que frente a lo existente "solo queda el camino crítico" ${ }^{55}$, y tras su crítica inmanente al pensamiento kantiano, sostuvo, además, que ese camino solo podía ser «un camino dialéctico» ( $\mathrm{Ng}$ IV, 4, 241).

\section{$\mathrm{X}$}

Benjamin quiso subtitular sus Pasajes «un cuento de hadas dialéctico» (una forma de rendir tributo a su pasión de lector y coleccionista de libros infantiles), un "cuento" que debía convertirse en una forma de hacer filosofía por medio de constelaciones a través de «imágenes dialécticas en detención» con las que trataba de superponer el pasado con el presente. Por medio de esas imágenes pretendía romper con la manera habitual de entender el tiempo, y hacer de las palabras «las velas del viento de la dialéctica»; unas velas con las que Adorno trató de aventurarse a salir de la isla kantiana y adentrarse en el océano de lo posible. Dialéctica negativa recogió ese espíritu de cuento de hadas sobre el que pensó Benjamin, conocedor de que estos seres de las narraciones de Perroult o de los Grimm usaban su saber para alcanzar la reconciliación. Es decir, una humanidad y una naturaleza no sometidas a coacción. Un saber que servía para sacar a la luz "la pobreza del mundo» y no capitular ante lo dado. Su hechizo -como se halla en el poema de Schiller que aparece en la Novena de Beethoven- podría hacer que se «una nuevamente lo que la acerba costumbre había separado: que todos los humanos vuelvan a ser hermanos» y se transforme el estado actual de las cosas. La Dialéctica negativa parece desear ese poder de las hadas: reavivar los objetos y desentumecer a los sujetos. Busca esa "magia», a la que denominó "experiencia metafísica», con la que trataba de hacer compatible lo que a Kant le resultaba antagónico y sobre lo que había erigido su «bloque». A través de esa experiencia, que surge de la inmanencia, desea rescatar las pretensiones de la trascendencia metafísica. Se trata de una experiencia fugaz y subjetiva, que asocia a los recuerdos de felicidad de la nińez; recuerdos tan inciertos como efímeros, y que vincula a lo sensorial e inaprehensible conceptualmente. Una felicidad que esboza como memoria de algo que quizá existió y que quizá vuelva a darse (GSA 6, 367):

El concepto de experiencia metafísica es antinómico en otra forma además de la enseñada en la dialéctica trascendental kantiana. El sujeto autónomo aspira a no

55 Ibid., A856/B884. 
dejarse imponer nada con lo que no esté de acuerdo. Todo lo pregonado por la metafísica sin recurrir a la experiencia del sujeto, sin contar con su participación personal, es impotente frente a esa aspiración. Sólo que lo inmediatamente evidente para el sujeto adolece de falibilidad y relatividad (ibid.).

Su pensamiento dialéctico y negativo se niega a que los dos polos del conocimiento (el sujeto y el objeto) se disuelvan el uno en el otro. Trata «de buscar en los objetos lo que han perdido al consolidarse como tales» (GSA 6, 31), «hacerlos hablar», darle expresión a eso que los sujetos le han sustraído, pero también potenciar un sujeto capaz de experimentar lo verdaderamente vivo. Para él, «no cabría [representar] el estado de reconciliación ni como la indiferenciada unidad de sujeto y objeto, ni como su antítesis hostil [...] [sino como paz] entre los individuos y entre ellos y lo otro. Esto es, como un estado de diferenciación sin sojuzgamiento en lo que lo diferente sea compartido» (GSA 10.2, 743). Y eso significa, con Kant, reflexionar continuamente "sobre la discordancia de la razón consigo misma" La dialéctica, insistía, «es una consecuencia necesaria [...] de la filosofía de Kant». Con ella coincidía en que no cabe reducir el polo subjetivo del conocimiento al objeto, ni darle primacía a éste sobre el sujeto, sin tener en cuenta el entramado de mediaciones que se daban entre ambos. Sería "el desgarramiento entre el sujeto y el objeto que se ha abierto paso hasta la consciencia» (GSA 6, 19). Frente al dominio de una razón identificadora que agota la experiencia y el conocimiento de la cosa en su fijación conceptual, Adorno, apoyándose en la noción kantiana de la "cosa en sí», defenderá la prioridad del objeto, sosteniendo que éste es más que su concepto. A diferencia de Kant, no habla de la actividad sintética de la subjetividad; una actividad que para él tiene un carácter procesual, dialéctico y discontinuo. De ahí que considerase necesario desestructurar la subjetividad constitutiva kantiana partiendo de la misma tensión que ésta mantiene con el objeto ${ }^{57}$. Trató de dinamizar las fisuras internas incrustadas en "el bloque kantiano" entre la experiencia y lo inteligible, integrando el carácter procesual que Hegel puso de manifiesto en la experiencia y en su conocimiento. Eso le llevó a poner en el centro de su dialéctica una categoría de mediación que no conoce un parar, que cuestiona la posibilidad de aprehender la realidad como si pudiese congelarse en una «foto fija»: «Las formas de la subjetividad [...] no son algo último para el conocimiento, pues éste es capaz de romper con ellas en el proceso de la experiencia» (GSA 6, 188). Fue consciente de que esa mediación asimétrica entre el sujeto y el objeto ${ }^{58}$ corría el peligro de acabar en identidad. La idea de que hay un plus en el objeto que el sujeto no alcanza es lo que para él impide que la experiencia sea un proceso hermenéutico con final fijo: «En los mecanismos subjetivos de la mediación se prolongan los de la objetividad

56 Kant, I. Op. cit., A465/B493.

57 Kant, I. sobre todo A226/B274 y ss.

${ }^{58}$ A pesar de que el sujeto está mediado subjetivamente, él considera que el objeto es la verdad del sujeto, que las posiciones del sujeto y el objeto no son intercambiables: «La objetividad puede ser concebida en potencia sin sujeto, no así sin objeto» (GSA 10.2, 747). 
que condena a todo sujeto, incluido al trascendental» (GSA 6, 173). Esta idea de no identidad entre el sujeto y el objeto, de un momento objetivo que permanece más allá del sujeto, está pensada, como se ha señalado, sobre la noción kantiana de "cosa en sí». Y es, para él, lo que evita el riesgo de que la dialéctica se suspenda. Su modo de entenderla le lleva a pensar lo que hay de irreductible bajo toda conceptualización, que siempre hay algo que es imposible identificar. Eso arma a la crítica contra las pretensiones totalitarias de la subjetividad constituyente y abre la posibilidad a experiencias nuevas y no reglamentadas, como ésas que se narran en los cuentos de hadas.

Lo que tiene de fantasía creativa esa dialéctica negativa consiste en chapotear en el cauce del lenguaje, en tratar de decir eso que no se puede decir, en "confiar en que el concepto pueda superar el concepto», consciente de que no dispone de más medios que de los conceptos, de que ha de minar la identidad con la propia identidad. Solo desde lo conceptual cabría aproximarse a lo no conceptual y resquebrajar la identidad: "La utopía del conocimiento sería penetrar con conceptos lo que no es conceptual", en desmitologizar los conceptos y volverlos contra sí mismos. Eso requiere, afirma, de la fantasía, "pues si se excluye [...] se está exorcizando el propio acto del conocimiento» (GSA 4, 137). La dialéctica negativa mantiene los pies en la inmanencia, pero buscando otra cosa: los sentidos que no están en lo dado y que tampoco cabe construir arbitrariamente. Su dialéctica coincide con la filosofía de Kant en impulsar el pensamiento más allá de los límites de una experiencia posible. Pero también en que "no hay que abandonarse a la desesperación escéptica, ni adoptar un dogmatismo tenaz $\$$. Se distancia de él al denunciar la reductio ad hominen que el sujeto efectúa sobre los objetos y en destacar que la potencia creadora del espíritu está encadenada a lo objetual. El materialismo de Adorno no renuncia al criticismo, pues "el primado del objeto necesita de la reflexión sobre el sujeto", pero teniendo en cuenta que el sujeto no es el constituens del objeto, sino tan solo su agente. De ahí la necesidad de «quebrar con la fuerza del sujeto, el engaño de la subjetividad constitutiva» (GSA 6, 10).

Desde sus inicios intelectuales Adorno mantuvo que la filosofía debía reflexionar continuamente sobre sí misma y criticarse sin consideración, pues había faltado a su promesa de ser idéntica con la realidad o de ser capaz de producirla. Fue consciente de que el enorme desarrollo de las ciencias, el pragmatismo imperante y el papel que las sociedades otorgan a los expertos convertían a la filosofía, cada vez más, en un resto anquilosado de la cultura con un incierto destino. «Kant -escribiódeclaró haber superado la filosofía de escuela con una concepción universal de la filosofía. Sin embargo, ahora la filosofía ha sido obligada a retroceder a su concepción de escuela» (GSA 6, 16). Estas páginas han pretendido mostrar que lecturas como las que hizo Adorno de Kant van más allá del mero historicismo y de la filologización de la filosofía, que leer a los clásicos, sin partir de un "punto de vista», puede tener un carácter productivo. Creía que mantener abierta la crítica, pensar el pensamiento,

59 Kant, I. Op. cit., A407/B434. 
podría permitir que la filosofía no se convirtiera en una reliquia y fuese capaz de sobrevivir a tiempos tan poco dados a ella. Sus textos aún siguen interpelándonos sobre la necesidad de repensar la filosofía.

Recibido: septiembre de 2018, ACEPTADO: noviembre de 2018 
